\title{
Competing in the Presence of Privacy Concerns: A Model of the Market for Customer Information
}

\author{
Ramnath K. Chellappa \\ Goizueta Business School, Emory University \\ Atlanta, GA 30322-2710 \\ ram@bus.emory.edu
}

\author{
Raymond G. Sin \\ School of Business and Management \\ Hong Kong University of Science and Technology \\ Clear Water Bay, Hong Kong \\ rsin@ust.hk
}

\begin{abstract}
There is "no free disposal" (NFD) in the consumption of online personalization services, as this activity inherently involves sharing of personal and preference information that creates disutilities to the consumer. Not only are more services not necessarily better for the consumer, but these services are also provided for free as firms extract value from the usage of consumer information rather than from directly pricing the services. Further, the services themselves may be provided to a consumer as a fixed-length toolbar/deskbar (fixed-services strategy) or with the option of choosing a subset of the portfolio of services offered (variable-services strategy). This paper models a duopoly of firms that are heterogeneous in their marginal value for consumer information (MVI) and interact through a two-stage dynamic game, where the firms choose a fixed- or variable-services strategy in the first stage and their level of services offering in the second. After examining a series of subgame equilibria, we arrive at distinct subgame-perfect Nash equilibriua (SPNEs) that allows us to characterize competition between firms of different MVI endowments. Our findings suggest that while there is no SPNE in a duopoly of two small firms, when one firm is small and the large, there is a unique SPNE in pure strategies where both firms offer fixed-services such that they segment the market. As the differences in their valuations increase, the larger firm continues to offer fixed-services while smaller firm enjoys the option of offering variable services. A duopoly of large firms results always results in symmetric SPNE; both firms offer variable services as long as one firm has very large MVI and both offer fixed-services otherwise. Interestingly while the former is consumer welfare maximizing, the latter results in a third of the market (consisting of privacy seekers) not being served. Our results lead to important managerial and policy implications, as well as interesting extensions to the existing location models.
\end{abstract}

Key words: personalization, privacy, spatial competition, Nash-equilibrium, welfare analysis 
1. Introduction

A recent Federal Trade Commission (FTC) workshop reports that a set of technologies called browser-embedded toolbars have exacerbated consumer concerns of privacy. Interestingly, while some groups characterize these as spyware, many others tout toolbarenabled personalization as the future of online services (FTC 2004). A toolbar is a Browser Helper Object (BHO), wherein once downloaded and embedded, it has the ability to monitor and report usage information (including Web sites visited, information filled in online forms, etc.) as well as to tailor future online interactions. More recently, Google's Deskbar, Microsoft's Live (now bundled with Vista) and Yahoo!'s Konfabulator technologies have begun to offer these services right from the desktop and are expected to replace current Web-based static personalization. Similar technologies have found their way to Smartphones (such as those running Windows Mobile operating systems) where personalization can provide even greater convenience to the consumer. Once embedded, firms can disallow consumers from turning off selected features, thus consumers may need to remove the entire toolbar (and hence forgo all personalization) if their comfort level in sharing information is below that of the amount acquired by the toolbar. As the FTC continues to assess its position on these technologies, toolbars have become ubiquitous with every online portal (Yahoo!, MSN, AOL, etc.) and many large online firms (eBay, Amazon, etc.) as well; e.g. currently over 618 Million searches originate from consumers using toolbars. Thus, one important objective of this paper is to investigate the regulatory implications regarding the allowance of such personalization technologies through a social welfare analysis.

The operational basis for these online firms that rely on consumer information is unique. Personalization services are entirely free of charge to the consumers; portal-like firms rely on their ability to sell browsing profiles to advertisers and targeted marketers (Dewan et al. 1999) while e-tailers use information acquired for personalization to manage their own inventory, marketing goals, and to enhance customer satisfaction and loyalty (Shankar et al. 2003). Indeed, the FTC also acknowledges the legitimate use of consumer information by businesses provided that such usage can also be beneficial to consumers (See FTC workshop report (2003)). From the consumer behavior perspective, online personalization is an example of goods with "no free disposal" (NFD) property, an economic classification of goods meaning that more of the good is not necessarily better. Recent marketing research on pricing access services online (Essegaier et al. 2002), observes, "Unlike physical goods for which "free disposal" is always an option and more is, in general, always better, service delivery is intrinsically participatory. Participation requires time commitment and physical effort on the part of consumers. Thus, there is no free disposal for service, and time cost and physical efforts limit the effectiveness of price incentives in altering consumer usage habit." An important cost intrinsically related to the usage of personalization services is the privacy costs that individuals incur when sharing their preference and usage information needed for tailoring services to their tastes (Volokh 2000). Therefore even if free of cost, not all consumers will prefer all services offered by the firm. This property poses many unique challenges to online firms and portals who incur costs of creating personalized services so as to acquire con- 
sumers' usage information. Thus, our paper examines a competitive market for privacy where firms have to strategically choose their level of personalization services offering for acquiring consumer information.

Further, we incorporate the possibility of online firms being similarly or differently endowed in their capacity to generate revenue or lower operating costs from mining and using consumer information and thus they may vary in the value placed on consumer information. For example, many large firms such as AOL and MSN do not simply resell their information, but they operate their own advertising networks with their own profiling technologies as well. On the other hand, many smaller firms and portals mostly act as a carrier of other's advertising networks such as from DoubleClick (DART network - at this time Google is working on integrating DoubleClick) and Atlas (Atlas Suite). While offering personalization is not costless, these technologies are ubiquitous and available to all, hence firms need to investigate their optimal service offerings when their competitors can also potentially offer identical services. Firm strategies in this regard have largely been unexplored in academic research, particularly given the NFD nature of consumers' utility and the non-price aspect of competition.

Our research examines a duopoly where firms are differentiated by their marginal value for information (MVI) and are engaged in a two-stage dynamic game where they choose their overall strategy of employing a fixed- or variable-services approach in the first stage. During this stage firms choose their technological infrastructure to decide between offering a fixed-length toolbar that requires consumers to use all of the services (and hence provide all corresponding information) or a variable-services approach where consumers can self-select into the optimal set of services to use. In the second stage they decide on their level of personalization service offering. By considering the various subgame equilibria in the second-stage we are able to derive the SPNE in pure strategies such that we characterize the competition between different firm types. This also allows us to study the welfare implications of competition in the market for information. The equilibrium condition where all consumers are able to self-select their optimal service level is of particular relevance to privacy-groups that are concerned about the possibility of consumers sharing more information than they would ideally want.

\subsection{Review of relevant literature}

A recent work in Management Science calls for the study of online personalization particularly in the presence of privacy concerns (Murthi and Sarkar 2003). Some have posited that a market for preference information will emerge where consumers will engage in transactions that involve privacy concerns (Rust et al. 2002). In this regard, behavioral work has suggested that consumers are more likely to accept loss of privacy if it accompanies some benefit (Laufer and Wolfe 1977), and consumer's decision to share information is based on some cost-benefit tradeoffs, known as the "privacy calculus" (Culnan and Bies 2003). Recent analytical work has abstracted this privacy calculus in the context of personalization through consumers' personalization for privacy ( $\mathrm{p} 4 \mathrm{p}$ ) tradeoff (Chellappa and Shivendu 2006; Chellappa and Shivendu 2007). However, to our best knowledge, there is no academic research that examines non-price competition in a market for goods with NFD property, e.g. in the markets for personalization services. 
Murthi and Sarkar (2003) point out the need to explore the segmentation aspects to a personalization market, and observe that when competing firms provide free products, differentiation along the lines of price competition becomes irrelevant. This paper addresses these aspects in that we model a market where firms differentiate themselves on the level of personalization services offered even when no price is being charged. However, note that for most goods in a vertically segmented market more quality (or any valued attribute) is strictly preferred by all consumers, i.e. while the marginal value for quality may differ amongst consumers, more is always better. Therefore, consumer utilities are typically strictly increasing in quality or monotonic (non-decreasing) concave. On the contrary, an important aspect of the personalization market is the NFD property of the services, where the general principle being that more is not always preferred to less. In such a market, every consumer has an ideal level of services she would like to use, similar to the ideal location point in a spatial market. This ideal point is a result of internalizing the tradeoff between gain from personalization and loss from privacy, which leads to a non-monotonic utility function that first increases then falls in services consumed (purely quality models with monotonic utilities are sometimes called "infinite ideal-point" - consumers homogeneously prefer an infinite amount of the good - models (Moorthy 1985)). While somewhat less studied than their "free disposal" counterpart, we commonly come across NFD goods when users have an intrinsic disutility from consuming beyond their satiation level (Nahata et al. 2003). Classic examples include identifying the right package size of travelers' toiletries (larger sizes are not always optimal), ideal level of sweetness of a drink (over-sweetness may not be preferred) and the optimal units of power production for a township (production creates pollution) (Rothwell and Rust 1997). Hence our model of competition also exhibits properties of horizontally segmented markets.

Findings in purely vertically segmented markets are well known in economics, marketing and information systems (which consider segmentation with zero marginal cost of serving additional consumers), where segmentation is generally superior except under shutdown conditions. On the other hand, findings in horizontally segmented markets are diverse and highly dependent on specific assumptions on transport costs and reservation prices (Hotelling 1929; Salop 1979). Equilibria may or may not exist and often the real source of non-existence of equilibrium in such markets is the non-quasiconcavity (caused by infinite reservation prices) as well as the discontinuity of the payoff functions (Economides 1984).

There is a limited number of papers that consider aspects of both vertical and location-based competition. For example, Gabszewicz and Thisse (1986) consider a market where there are vertical and horizontal differentiations with quadratic transport costs albeit with infinite reservation prices for consumers. Research in marketing has also considered cases where consumers vary both in their marginal value for quality as well as in their taste preferences, although these attributes are assumed to be independent of each other (Desai 2001). While closer to our model in spirit, it is to be noted that aspects of horizontal and vertical differentiation in our case emerge endogenously from the NFD utility and consumer heterogeneity. The above differences combined with the nonprice, zero marginal cost and zero versioning cost of services in our market require us to re-examine any extant segmentation find- 
ings. Our setup relates to an extant work on product and price competition with structural similarities in the payoff and best response functions (Moorthy 1988), while still being different in the following aspects:

1. We model a good with no free disposal property where the consumer's utility function is non-monotonic concave.

2. We model a market with non-price competition, thus restricting the strategic instrument available to the firms.

3. There are no marginal costs of serving additional consumers and there are no costs associated with offering a subset of the maximum produced services. The latter is referred to as "costless versioning" or "costless degradation" elsewhere (Varian 1997)

4. We make no a priori assumptions on market coverage or relative firm characteristics.

In §2 we present the basic model setup when firms pursue fixed- vs. variable-services and introduce the consumer tradeoffs. In $\S 3$, we derive equilibrium service offerings for different duopolistic markets where one or both firms pursue fixed- or variableservices strategy. We then derive the different SPNEs in pure strategies. We conclude this section with an investigation of welfare implications for each type of the market setup discussed earlier. $\S 4$ examines the policy implications of our findings, and concludes with a discussion of theoretical and managerial implications of our analyses.

\section{Model}

We shall first setup the consumers' utility function before examining the timeline of the duopoly game. Consumers are known to engage in a privacy calculus in their decision to use personalization services as they incur privacy costs in sharing information needed for this activity (Culnan and Bies 2003). This willingness to share information is based on the consumer's perceived benefits of disclosure balanced with its risks (Derlega et al. 1993). Consumer behavior in this context has been modeled by prior research (Chellappa and Shivendu 2006) as a function of consumers' marginal value for personalization $p$ and their coefficient of information privacy concerns $r$. We can write a consumer $C$ 's utility as a function of personalization services consumed

$$
u\left(s, p_{c}, r_{c}\right)=p_{c} s-r_{c} s^{2}
$$

It is important to note two salient aspects of consumption here: First, services are provided for free. Consumers do not pay any price to the firm. Second, more services are not necessarily better, i.e. there is no free disposal (NFD) in personalization services. There is an intrinsic disutility associated with consuming personalization services in the form preference and personal information that needs to be shared for the provision $s$ services (given by $r_{c} s^{2}$ ). Note that the utility function is non-monotonic (an inverted-U function) in services consumed, and is characterized by the two levels, the utility maximizing $s_{c}^{*}=\arg \max u\left(s, p_{c}, r_{c}\right)$, and break-even $\left(s_{c}^{0}: u\left(s, p_{c}, r_{c}\right)=0\right)$ service levels respectively. For the utility function 
described by equation (1), we can see that $s_{c}^{0}=\frac{p_{c}}{r_{c}}$ and $s_{c}^{*}=\frac{p_{c}}{2 r_{c}}$. The ratio $\frac{p}{r}$ is known as the consumers' personalization for privacy $(\mathrm{p} 4 \mathrm{p})$ ratio and is a critical parameter for analysis of consumer behavior as it determines both their indifference and optimal service levels.

Empirical research finds that consumers may vary in their value for personalization and concerns for privacy (Chellappa and Sin 2005). Consider a market where consumers are uniformly distributed in their p4p ratio given by $\frac{p}{r} \sim U[0, b]$. This also allows us to represent the two consumer-behavior characterizing levels along the same dimensions given by $s_{c}^{0} \sim U[0, b]$ and $s_{c}^{*} \sim U\left[0, \frac{b}{2}\right]$. We shall generally refer to consumers with low $\mathrm{p} 4 \mathrm{p}$ ratios as privacy-seekers and those with high $\mathrm{p} 4 \mathrm{p}$ values as convenience-seekers. A summary explanation of major notations used in this paper is presented in Table 1 in the appendix.

\subsection{Online firm strategies}

Firms vary in their ability to use consumer information by virtue of the extent to which this information can be exploited to their own purposes, represented by their marginal value for information (MVI). For example, portals such as Yahoo! and $\mathrm{AOL}$ that run their own advertising networks do not simply resell usage/preference information; rather they have a portfolio of advertising related products unlike portals such DogPile and AskJeeves. Yahoo! Search Marketing division offers products such as Search Optimizer and Marketing Console that are geared towards small to medium firms, and provides a fully customized advertising program for firms that have a budget of over $\$ 10,000$ per month. Similarly, retailers like Amazon.com that carry many product categories and engage in cross-selling strategies have greater MVI's than firms that sell one type of product or use their service to host advertisements.

Offering personalization services is not costless; firms either incur their own costs of building a toolbar, or they incur licensing and technology costs from buying from firms such as BestToolBars.net and ezToolbar.com. In addition, firms offering personalization also incur costs of licensing content, building trust through alliances with trusted third-parties (e.g., TRUSTe, WebCPA, Verisign), and implementing security mechanisms to comply with FTC requirements (FTC 2000) and special legislative requirements such as Children's Online Privacy Protection Act (COPPA) and Health Insurance Portability and Accountability Act (HIPPA) as well (Bloom et al. 1994; Scott 1999; Anonymous 2001).

Firms can employ a fixed- or variable-services strategy when offering personalization services. Typically, the online firms can operationalize these strategies in one of the following two ways through their toolbar (or desktop) technologies:

1. A toolbar of fixed length - where the firm contracts to personalize a predefined number of services, monitoring and acquiring information that corresponds to the entire set of services. The consumer is faced with a take-it or leave-it offer where they 
will use as long as the utility is non-negative for the service level, i.e., $s \in\left(0, s_{c}^{0}\right]$. A9.com's (affiliated with Amazon.com) toolbar is a classic example of this approach where a consumer has to agree to all the information being monitored (which is fully disclosed in the firm's privacy policy) or to not use the toolbar at all. We increasingly observe this bundled approach in many mobile devices as well. Throughout the paper we shall refer to this as the fixed-services strategy.

2. Toolbars of variable lengths - where the firm offers a toolbar with its full list of services and allows consumers to choose a subset. In this case when consumers vary in their $\mathrm{p} 4 \mathrm{p}$ tradeoffs, each consumer will use a different services level according to her optimal level $s_{c}^{*}$ if available, else the level provided by the firm (formally $\min \left\{s_{c}^{*}, s\right\}$ ). Many toolbars including Google and Yahoo! follow this approach where consumers have the option to turn off personalization based on increasingly sensitive information, e.g., the PageRank (called Web Rank in Yahoo!) feature can be removed when using Google toolbar services. This ability to create and offer lower versions without incurring additional costs is often referred to costless degradation in versioning literature (Varian 1997). In this paper we shall refer to this as the variable-services strategy.

Unlike in Sundararajan (2004) and Chellappa and Shivendu (2008), we investigate the strategies of a capacity constrained vendor who offers a maximum of $s_{i}\left(s \in\left[0, s_{i}\right]\right)$ services. We assume a quadratic cost for the one time creation of services (a kind of fixed cost but endogenized in the optimization problem), but importantly (i) there is no marginal cost of serving an additional consumer and (ii) there is costless-degradation. We can now construct the objective function of a firm $i$ as

$$
\max _{s_{i}} \sigma_{i} A(s)-s_{i}^{2} \quad \text { s.t. } \quad u(s, p, r) \geq 0
$$

where $\sigma_{i}$ is the marginal value for information (MVI) of a firm $i$ and $A(s)$ is the aggregate information acquired by a firm from the usage of $s$ personalization services.

In this paper, we consider a duopoly where the two firms differ in their marginal value for information $\left.\sigma_{i}\right|_{i \in\{1,2\}}$ with identical costs of producing personalization services. The identical cost function not only rules out a trivial explanation that any difference in firm strategies is due to differences in costs, but is also consistent with the ubiquitous availability and open-standard nature of personalization technologies. The ability to use information, however, is indeed a function of firms' business strategies and endowments and may affect their overall personalization offerings. However, no assumption is made on the relative values of the two MVIs. 


\section{Competition in a duopoly}

We model the duopolistic competition as a two-stage game with complete but imperfect information. In the first stage, the firms decide whether they will follow a fixed- or a variable-services strategy approach. In the second stage the firms choose their respective service levels $s_{1} \in S_{1}$ and $s_{2} \in S_{2}$. Note that the strategy spaces are bounded by $b \quad\left(S_{1}, S_{2}=[0, b]\right)$, as no consumer would use beyond this level; hence no firm will ever consider a strategy of offering services beyond this limit. We seek subgame-perfect Nash equilibria (SPNE) in pure strategies. So we need to first consider the series of possible subgame equilibria.

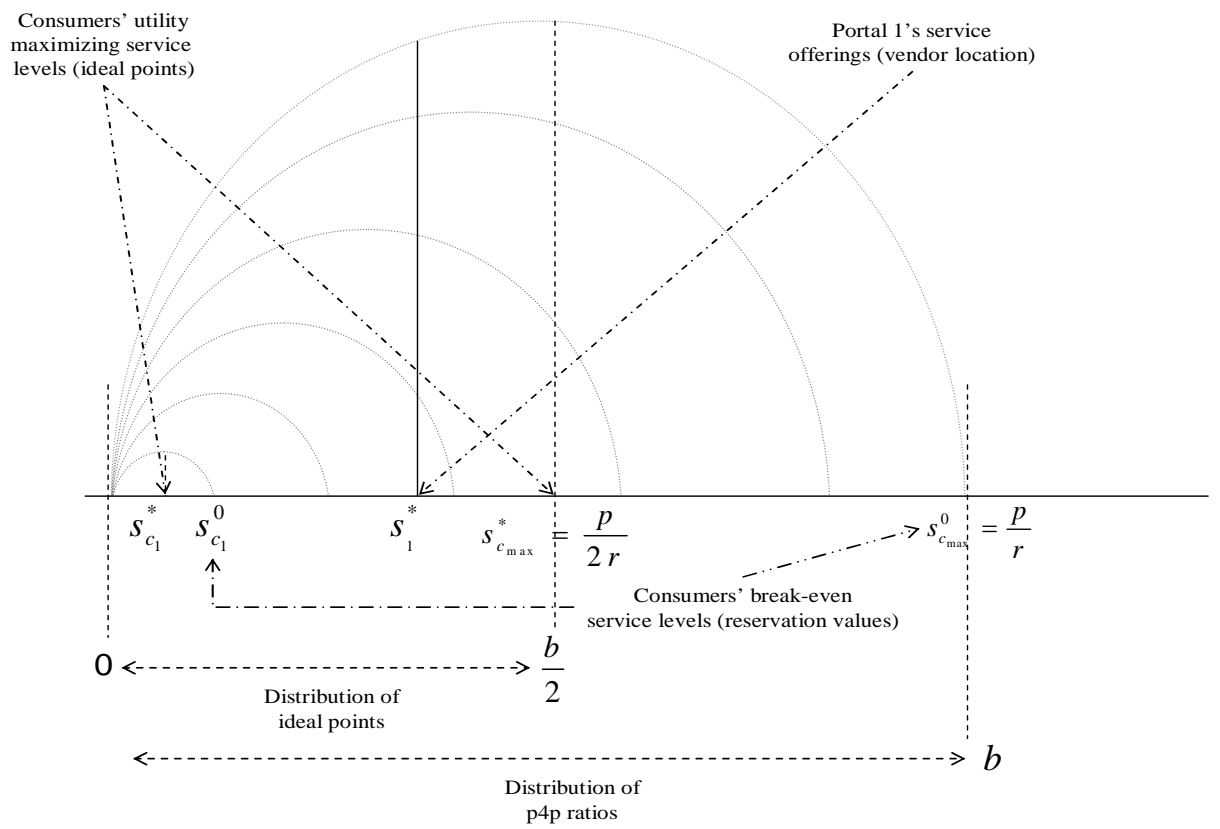

Figure 1: Distribution of consumer preferences and firm locations on a line

Figure 1 characterizes our personalization market as a linear one where each consumer's location or ideal service level $s_{c}^{*}$ is uniformly distributed from 0 to $\frac{b}{2}$. If a firm offers a certain service level $s_{1}$ at some distance $x$ from the ideal point of a consumer, we can see that the disutility given by $\left|u\left(p_{c}, r_{c}, s_{c}^{*}\right)-u\left(p_{c}, r_{c}, s_{1}\right)\right|$ will be $r x^{2}$. In other words, consumers suffer a convex transportation cost, along the lines of D'Aspremont et al. (1979), for which equilibrium in locations exists under certain condition. While firms incur convex costs of locating themselves on the line (normally ignored in spatial models), the zero-marginal costs and zero versioning costs of services (costless degradation - a lower service-level can be offered costlessly once a toolbar of higher services is built) combined with the NFD property create unique competitive situations non-existent in physical goods markets. While the fixed-services approach appears to be structurally similar to physical goods model setup (i.e., once a firm has located, all consumers have to buy from that point), the variable-services strategy creates a unique possibility wherein if the firm 
offers a service level $s_{1}$, he can costlessly serve all consumers with $s_{c}{ }_{c}<s_{1}$ at their ideal levels. This can be considered as the firm costless creating a franchise at each consumer location to his left. Also note that we do not assume a priori as to whether the market is covered (which is the case in most spatial models) or not, i.e., consumers do not have infinite reservation. In view of these differences, it is not clear if any equilibrium possibilities exist at all; hence this is an interesting model to analyze from a location model perspective as well.

We now proceed to solving for equilibria using backward induction. In the service-level subgames, firms know whether the competitor has adopted a fixed- or a variable-services approach in the previous stage. There are four possible subgames, namely fixed-fixed, fixed-variable, variable-fixed and variable-variable. Before identifying the SPNEs, we shall first derive the various subgame equilibria.

\subsection{Subgame when both firms employ fixed-services strategy}

We first consider the case when both firms offer a toolbar of fixed length, i.e., a take-it or leave-it offer where consumers who accept the contract agree to the acquisition of a fixed amount information on their usage. The individual rationality constraint requires that a consumer picks a service where her utility is non-negative, while the incentive compatibility condition requires that she chooses the firm that provides her the highest utility, i.e., she will choose Firm 1 if $u\left(p_{c}, r_{c}, s_{1}\right)>u\left(p_{c}, r_{c}, s_{2}\right)$. This can be written as

$$
p s_{1}-r s_{1}^{2}>p s_{2}-r s_{2}^{2} \Rightarrow \frac{p}{r}\left(s_{1}-s_{2}\right)>s_{1}^{2}-s_{2}^{2}
$$

And if $s_{1}<s_{2}$ (case a), equation (3) implies $\frac{p}{r}<s_{1}+s_{2}$. Notice that consumers with $s_{c}^{0}<s_{1}$ would not use any services at all, therefore consumers whose break-even service level $s_{c}^{0} \in\left[s_{1}, s_{1}+s_{2}\right)$ would use Firm 1's services and the remaining consumers $s_{c}^{0} \in\left[s_{1}+s_{2}, b\right]$ would use Firm 2's services. By symmetry, we know that if Firm 1 offers more services than Firm $2\left(s_{1}>s_{2}\right.$, case "c"), consumers with $s_{c}^{0} \in\left[s_{1}+s_{2}, b\right]$ will use Firm 1's services. If both firms offer the same level of service level ( $s_{1}=s_{2}$, case "b"), then given that consumers are indifferent between the two firms, Firm 1 will get half the market of all consumers using the services, i.e. half of the consumers whose break-even service level are $s_{c}^{0} \in\left[s_{1}, b\right]$. We can formally write Firm 1's profit functions in the second stage when both firms pursue a fixed-services strategy (we use superscripts $F$ and $V$ for fixed- and variable-services strategies, respectively) as 


$$
\pi_{1}^{F}=\left\{\begin{array}{l}
\pi_{1 a}^{F}=\sigma_{1} \int_{s_{1}}^{s_{1}+s_{2}} s_{1} U\left(s_{c}^{0}\right) d\left(s_{c}^{0}\right)-s_{1}^{2} \quad \text { if } \quad\left(s_{1}<s_{2}\right) \\
\pi_{1 b}^{F}=\frac{1}{2} \sigma_{1} \int_{s_{1}}^{b} s_{1} U\left(s_{c}^{0}\right) d\left(s_{c}^{0}\right)-s_{1}^{2} \quad \text { if } \quad\left(s_{1}=s_{2}\right) \\
\pi_{1 c}^{F}=\sigma_{1} \int_{s_{1}+s_{2}}^{b} s_{1} U\left(s_{c}^{0}\right) d\left(s_{c}^{0}\right)-s_{1}^{2} \quad \text { if } \quad\left(s_{1}>s_{2}\right)
\end{array}\right.
$$

By symmetry, we can construct Firm 2's profit function. Notice that the payoff functions of both firms are discontinuous in the service space; such a discontinuity raises the concern of whether pure-strategy equilibrium exists. However, for our analyses, we consider only pure-strategy equilibria for two reasons: First, mixed strategies severely limit the explanatory power of the model; second, work by Dasgupta and Maskin (1986) suggests that it is not the discontinuity itself, but rather failure of the payoff functions to be quasi-concave that is the reason for the non-existence of equilibrium in pure-strategies. They propose that under certain conditions (quasi-concavity, upper semi-continuity and graph continuity of the payoff functions), even a game with functions that have limited continuity can possess a pure-strategy Nash equilibrium. Later work has argued these conditions are far too restrictive and only certain conditions ${ }^{1}$ on the aggregator function need to be satisfied for a pure strategy equilibrium to exist (Baye et al. 1993). In the appendix we show that our profit functions satisfy these conditions.

We shall now proceed to analyzing the strategic interactions between the two firms. Firm 1's strategy is a best response to the strategy of Firm 2 if it maximizes $\pi_{1}^{F}\left(\max \left\{\pi_{1 a}^{F}, \pi_{1 b}^{F}, \pi_{1 c}^{F}\right\}, s_{2}\right)$ in the strategy space $S_{1}$ for any given $s_{2}$. In considering the best response of Firm 1, not only does he decide on the service level but also determines whether to offer a service level that is lower than, equal to or greater than the competing firm. By symmetry, we can see that Firm 2 engages in a similar consideration in responding to services offered by Firm 1 as well. Independently, profits in their defined regions are all strictly concave, hence interior optima are candidates for equilibrium outcomes. However, note that for certain firm parameters (MVIs), the functions do not attain their maximum within the defined regions, e.g., when $\sigma_{1}>2 b, \pi_{1 a}^{F}$ is still increasing as $s_{1}$ approaches $s_{2}$, implying that a firm of this type will attempt to "undercut" his competitor by offering slightly more services. Hence when a firm's $\mathrm{MVI}$ is greater than $2 b$, offering services fewer than those offered by his competitor can never be a profit-maximizing strategy in equilibrium. Similarly, when a competitor offers a service level $s_{2} \geq \frac{b \sigma_{1}}{2 b+3 \sigma_{1}}$, irrespective of his own MVI, it is not optimal for Firm 1 to offer more than Firm 2 as $\pi_{1 c}^{F}$ is monotonically decreasing in $s_{1}$; hence region $c$ cannot be an

\footnotetext{
1 The sufficient conditions are Diagonal Transfer Continuity and Diagonal Transfer Quasiconcavity. See Appendix for details.
} 
equilibrium candidate for this particular firm pair. Therefore, if the Nash equilibrium pair is given by $s_{1}^{F^{*}}, s_{2}^{F^{*}}$, then from Firm 1 's perspective and for any Firm 2 there might be

1. An asymmetric equilibrium where Firm 1 offers fewer services than Firm 2, given by $s_{1}^{F^{*}}, s_{2}^{F^{*}}\left(s_{1}^{F^{*}}<s_{2}^{F^{*}}\right)=\left\{\frac{\sigma_{1}}{2 b} s_{2}^{F^{*}}, s_{2}^{F^{*}}\right\}$ and Firm 1's MVI is $\sigma_{1}<2 b$.

2. An asymmetric equilibrium where he offers more services than Firm 2, given by $s_{1}^{F^{*}}, s_{2}^{F^{*}}\left(s_{1}^{F^{*}}>s_{2}^{F^{*}}\right)=\left\{\frac{\left(b-s_{2}^{F^{*}}\right) \sigma_{1}}{2\left(b+\sigma_{1}\right)}, s_{2}^{F^{*}}\right\}$ and Firm 1's MVI $\sigma_{1}<\frac{2 b s_{2}^{F^{*}}}{b-3 s_{2}^{F^{*}}}$.

3. A symmetric equilibrium where he offers the same services as Firm 2, given by $s_{1}^{F^{*}}, s_{2}^{F^{*}}\left(s_{1}^{F^{*}}=s_{2}^{F^{*}}\right)=\left\{s_{2}^{F^{*}}, s_{2}^{F^{*}}\right\}$ for any MVI of Firm 1.

In order for the service-pair $\left\{s_{1}^{F^{*}}, s_{2}^{F^{*}}\right\}$ to be an equilibrium candidate, it is necessary for $\max \left\{\pi_{1}^{F}\left(., s_{2}^{*}\right)\right\}=\pi_{1 a}^{F}\left(s_{1}^{F^{*}}\right)$ and $\quad \max \left\{\pi_{2}^{F}\left(s_{1}^{*},.\right)\right\}=\pi_{2 c}^{F}\left(s_{2}^{F^{*}}\right) \quad$ in $\quad$ case $\quad 1$ $\max \left\{\pi_{1}^{F}\left(., s_{2}^{*}\right)\right\}=\pi_{1 c}^{F}\left(s_{1}^{F^{*}}\right)$ and $\quad \max \left\{\pi_{2}^{F}\left(s_{1}^{*},.\right)\right\}=\pi_{2 a}^{F}\left(s_{2}^{F^{*}}\right)$ in $\quad$ case $\quad$ or $\max \left\{\pi_{1}^{F}\left(., s_{2}^{*}\right)\right\}=\pi_{1 b}^{F}\left(s_{1}^{F^{*}}\right)$ and $\max \left\{\pi_{2}^{F}\left(s_{1}^{*},.\right)\right\}=\pi_{2 b}^{F}\left(s_{2}^{F^{*}}\right)$ in case $3 . \quad$ Combining 1 and 2 and by symmetry, we find that an asymmetric equilibrium can exist between two firms (suppose that Firm 1 offers the lower service level) only if $\sigma_{1}<2 b$ and $\sigma_{2}<\frac{2 b s_{1}^{F^{*}}}{b-3 s_{1}^{F^{*}}}$. From Figure 2, we can see that for such instances the payoffs of both firms are well behaved in that they are continuous but for upward jumps (Milgrom and Roberts 1994). This property again points towards the existence of pure-strategy Nash equilibria. In order to identify the MVI combinations for which there exists an equilibrium, we find bounds on the firm parameters (MVls $\sigma_{1}$ and $\sigma_{2}$ ) that satisfy the above requirements, i.e. for which two types of firms will the market result in an equilibrium outcome. While algebraically tedious (the proof is relegated to the appendix), our approach provides lucid solutions to firm and regulator problems, and allows us to derive managerially relevant insights on firm competition under privacy. 
Lemma 1. In a subgame where both firms adopt a fixed-services strategy, there exists an asymmetric subgame equilibrium

in the second stage given by $\left(s_{1}^{F^{*}}, s_{2}^{F^{*}}\right)=\left(\frac{b \sigma_{1} \sigma_{2}}{4 b\left(b+\sigma_{2}\right)+\sigma_{1} \sigma_{2}}, \frac{2 b^{2} \sigma_{2}}{4 b\left(b+\sigma_{2}\right)+\sigma_{1} \sigma_{2}}\right)$ when $\sigma_{1} \in[0,2 b)$ and $\sigma_{2} \in\left[\frac{8 b^{2} \sigma_{1}}{4 b^{2}-\sigma_{1}^{2}}, \infty\right) \mathbf{\square}$

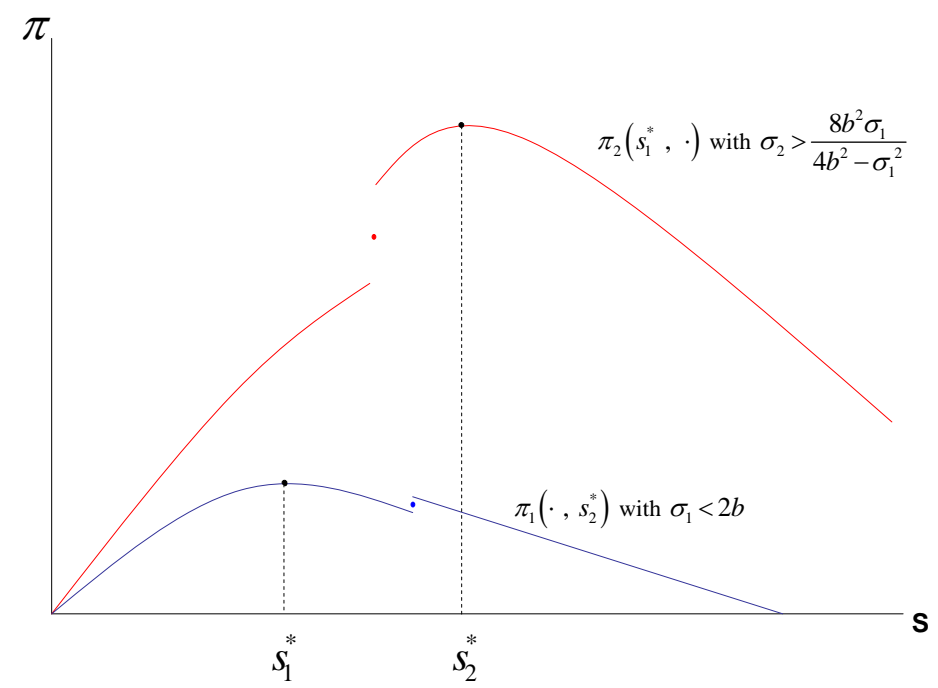

Figure 2: Profit functions under asymmetric equilibrium when both firms offer the fixed-services strategy

Note that while the services offered by both firms are increasing in $\sigma_{2}$ of the high MVI firm, the services offered by

high MVI firm $\left(s_{2}\right)$ is decreasing in $\sigma_{1}$ and the low MVI's services $\left(s_{1}\right)$ continue to increase in its own MVI. The intuition behind this is that if the MVIs are sufficiently far apart, the firms will make themselves attractive to very distinct segments and as $\sigma_{1}$ approaches $2 b$, the low MVI firm will begin to offer services that are now attractive to some consumers (who were using more than their optimal levels) of its competitor. Hence for the large MVI firm, the cost of offering high number of services is not offset by the demand captured and will therefore lower his service level. Further, we know that the number of consumers who are not served $\left(s_{c}^{0}<s_{1}^{F^{*}}\right)$ increases in $\mathrm{MVI}$, while on the other hand some consumers (with high p4p ratio) might receive services closer to their optima. This portends interesting consumer (and hence social) welfare implications that we shall explore later. In fact, since $\lim _{\sigma_{1} \rightarrow 2 b} s_{1}^{F^{*}}=s_{2}^{F^{*}}$, we not only know that the threshold is important in maintaining the asymmetric equilibrium but also that there is potentially a symmetric equilibrium if the MVIs of both firms are sufficiently high. 


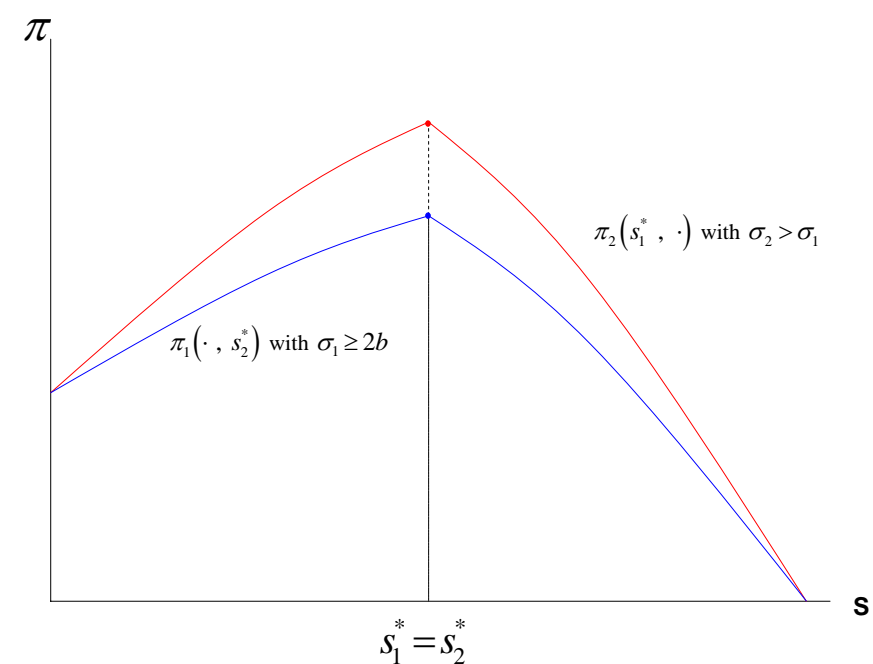

Figure 3: Profits of firms under symmetric subgame equilibrium when both firms offer the fixed-services strategy

LEMmA 2. In the subgame where both firms employ a fixed-services strategy, there exists a symmetric equilibrium given by

$\left(s_{1}^{F^{*}}, s_{2}^{F^{*}}\right)=\left(\frac{b}{3}, \frac{b}{3}\right)$ when $\left\{\sigma_{1}, \sigma_{2}\right\} \in[2 b, \infty)$

Lemma 2 suggests that when both firms have high MVI, given that both employ a fixed-services strategy in the first stage, the only feasible equilibrium is characterized by firms offering the same level of services and sharing the market equally (see Figure 3 for a graphical representation of profits of the high MVI firms with respect to services offered). Note that not only is the equilibrium service level purely a function of consumers' $p 4 p$ distribution, but also firms need not be characterized by identical MVls for a symmetric equilibrium to exist; it is only necessary that both firms have MVIs that are weakly higher than a threshold ( $2 b$ ).

3.2 Subgame when both firms employ variable services strategy

We now consider the scenario where firms offer a toolbar of certain length, but allow consumers to use only a subset of services by turning off information acquisition for some services (thus forgoing personalization benefit from these services as well). The NFD property of the good plays an important role here in that with the option of choosing their own service levels, consumers will choose only their optimal service level $s_{c}^{*}$ if available. Since consumers will be indifferent between the services offered by the two firms, both firms will share the consumer segment with $s_{c}^{*} \leq \min \left\{s_{1}, s_{2}\right\}$. The remaining consumers $\left(s_{c}^{*}>\min \left\{s_{1}, s_{2}\right\}\right)$ will use services from the firm offering a higher service level, because they can no longer be satisfied by the other firm. However, note that this segment of consumers can only use their ideal level of services up to the highest level available in the market; beyond which they can only use the exact amount that is offered. Thus, we can formally write Firm 1's profit functions as 


$$
\pi_{1}^{V}=\left\{\begin{array}{cr}
\pi_{1 a}^{V}=\frac{1}{2} \sigma_{1} \int_{0}^{s_{1}} s_{c}^{*} U\left(s_{c}^{*}\right) d\left(s_{c}^{*}\right)-s_{1}^{2} & \text { if }\left(s_{1}<s_{2}\right) \\
\pi_{1 b}^{V}=\frac{1}{2} \sigma_{1}\left[\int_{0}^{s_{1}} s_{c}^{*} U\left(s_{c}^{*}\right) d\left(s_{c}^{*}\right)+s_{1} \int_{s_{1}}^{\frac{b}{2}} U\left(s_{c}^{*}\right) d\left(s_{c}^{*}\right)\right]-s_{1}^{2} & \text { if }\left(s_{1}=s_{2}\right) \\
\pi_{1 c}^{V}=\frac{1}{2} \sigma_{1} \int_{0}^{s_{2}} s_{c}^{*} U\left(s_{c}^{*}\right) d\left(s_{c}^{*}\right)+\sigma_{1}\left[\int_{s_{2}}^{s_{1}} s_{c}^{*} U\left(s_{c}^{*}\right) d\left(s_{c}^{*}\right)+s_{1} \int_{s_{1}}^{\frac{b}{2}} U\left(s_{c}^{*}\right) d\left(s_{c}^{*}\right)\right]-s_{1}{ }^{2} \text { if }\left(s_{1}>s_{2}\right)
\end{array}\right.
$$

For some firm parameters, offering a service level lower than that of the competitor is a strictly dominated strategy; when

$\sigma_{1} \leq 2 b, \pi_{1 a}^{V}$ is negative regardless of the service level offered by Firm 2 . The intuition is that when both firms offer variable services, the firm offering lower service level incurs the full cost of offering the service while being assured of only half the corresponding market. However, if $\sigma_{1}>2 b, \pi_{1 a}^{V}$ is still increasing as $s_{1}$ approaches $s_{2}$, implying that this firm will prefer to offer the same or higher number of services as his competitor. Extending this logic to Firm 2 and by symmetry we can preclude the possibility of an asymmetric equilibrium when variable services define the market. Therefore if the Nash equilibrium pair is given by $s_{1}^{V^{*}}, s_{2}^{V^{*}}$, then from Firm 1's perspective and for any Firm 2 there might only be a symmetric equilibrium where he offers the same services as Firm 2, given by $s_{1}^{V^{*}}, s_{2}^{V^{*}}\left(s_{1}^{V^{*}}=s_{2}^{V^{*}}\right)=\left\{s_{2}^{V^{*}}, s_{2}^{V^{*}}\right\}$ for any MVI of Firm 1. In order for the servicepair $\left\{s_{1}^{V^{*}}, s_{2}^{V^{*}}\right\} \quad$ to $\quad$ be $\quad$ an equilibrium candidate, it is necessary that $\max \left\{\pi_{1}^{V}\left(., s_{2}^{*}\right)\right\}=\pi_{1 b}^{V}\left(s_{1}^{V^{*}}\right) \quad$ and $\max \left\{\pi_{2}^{V}\left(s_{1}^{*},.\right)\right\}=\pi_{2 b}^{V}\left(s_{2}^{V^{*}}\right)$. Similar to the previous cases, we derive boundaries on the firm parameters $\left(\sigma_{1}, \sigma_{2}\right)$ so as to explore for the possibility for any equilibrium strategy.

LEMMA 3. In the subgame where both firms pursue a variable-services, a symmetric equilibrium is the only outcome and is given by $\left(s_{1}^{V^{*}}, s_{2}^{V^{*}}\right)=\left(\frac{b}{2}, \frac{b}{2}\right)$ when $\left\{\sigma_{1}, \sigma_{2}\right\} \in(2 b, \infty)$.

3.3. Subgame when one firm pursues fixed- while the other pursues variable-services strategy Without loss of generality, assume Firm 2 to be the one that offers a toolbar of fixed length, while Firm 1 allows consumers to choose services in a variable fashion. First consider the case when both firms offer different levels of services $\left(s_{1} \neq s_{2}\right)$. If Firm 1 offers fewer number of services than $2\left(s_{1}<s_{2}\right)$, then all consumers with surplus maximizing number of services lower than that offered by Firm $1\left(s_{c}^{*} \leq s_{1}\right)$ would choose Firm 1 , because they can freely choose their ideal level 
to consume. The remaining consumers would choose Firm 1 if $u\left(p_{c}, r_{c}, s_{1}\right)>u\left(p_{c}, r_{c}, s_{2}\right)$. We can see that consumers whose p4p ratio $\frac{p}{r} \in\left[2 s_{1}, s_{1}+s_{2}\right)$ will still use Firm 1's services. However, if Firm 1 offers more services than Firm 2 $\left(s_{1}>s_{2}\right)$, all consumers will choose Firm 1 and use their individual utility-maximizing number of services. If both firms offer the same level of services $\left(s_{1}=s_{2}\right)$, Firm 1 would capture all consumers whose $s_{c}^{*} \leq s_{1}$ and half the market of all remaining consumers. Thus the profit function of the firm offering variable services can be written as

$$
\pi_{1}^{\tilde{V}}=\left\{\begin{array}{l}
\tilde{V}=\sigma_{1}\left[\int_{0}^{s_{1}} s_{c}^{*} U\left(s_{c}^{*}\right) d\left(s_{c}^{*}\right)+\int_{2 s_{1}}^{s_{1}+s_{2}} s_{1} U\left(s_{c}^{0}\right) d\left(s_{c}^{0}\right)\right]-s_{1}^{2} \quad \text { if } \quad\left(s_{1}<s_{2}\right) \\
\pi_{1 b}^{\tilde{V}}=\sigma_{1}\left[\int_{0}^{s_{1}} s_{c}^{*} U\left(s_{c}^{*}\right) d\left(s_{c}^{*}\right)+\frac{1}{2} \int_{s_{1}}^{\frac{b}{2}} s_{1} U\left(s_{c}^{*}\right) d\left(s_{c}^{*}\right)\right]-s_{1}^{2} \quad \text { if }\left(s_{1}=s_{2}\right) \\
\tilde{\widetilde{V}}=\sigma_{1}\left[\int_{0}^{s_{1}} s_{c}^{*} U\left(s_{c}^{*}\right) d\left(s_{c}^{*}\right)+\int_{s_{1}}^{\frac{b}{2}} s_{1} U\left(s_{c}^{*}\right) d\left(s_{c}^{*}\right)\right]-s_{1}^{2} \quad \text { if }\left(s_{1}>s_{2}\right)
\end{array}\right.
$$

And the profit function of the firm offering fixed-services can be written as

$$
\pi_{2}^{\widetilde{F}}= \begin{cases}\pi_{2 a}^{\widetilde{F}}=\sigma_{2}\left[\int_{s_{1}+s_{2}}^{b} s_{2} U\left(s_{c}^{0}\right) d\left(s_{c}^{0}\right)\right]-s_{2}^{2} & \text { if }\left(s_{1}<s_{2}\right) \\ \pi_{2 b}^{\widetilde{F}}=\sigma_{2}\left[\frac{1}{2} \int_{s_{2}}^{\frac{b}{2}} s_{2} U\left(s_{c}^{*}\right) d\left(s_{c}^{*}\right)\right]-s_{2}^{2} & \text { if }\left(s_{1}=s_{2}\right) \\ \pi_{2 c}^{\widetilde{F}}=-s_{2}^{2} & \text { if }\left(s_{1}>s_{2}\right)\end{cases}
$$

Let the Nash equilibrium pair be given by $s_{1}^{*}, \tilde{F}_{2}^{*}$. We can immediately observe that when the firm offering higher number of services allows consumers to choose their preferred level, it is never optimal for the firm offering a smaller length toolbar to pursue a fixed-services strategy. The intuitive reason is that consumers would undoubtedly use their ideal service level if given the choice, which results in a negative profit for the firm offering fixed-services strategy (i.e., $s_{1}^{\widetilde{F}}<s_{2}^{\tilde{V}}$ is never an equilibrium possibility). Notice that similar to section 3.1, for some firm parameters the profit functions do not attain their maximum within the defined regions: when $\sigma_{1}>2 b, \pi_{1 a}^{\tilde{V}}$ of the firm offering variable services is still increasing as $s_{1}$ approaches $s_{2}$, implying that when a firm's MVI is greater than $2 b$, offering services fewer than that offered by his competitor is cannot be an equilibrium strategy. Since any asymmetric equilibrium implies $s_{2} \widetilde{F}^{*}>s_{1} \tilde{V}^{*}$, from Firm 1's perspective and for any Firm 2 there might be 
1. An asymmetric equilibrium where Firm 1 offers fewer services than Firm 2 , given by $s_{1}^{V^{*}}, s_{2}^{F^{*}}\left(s_{1}^{V^{*}}<s_{2}^{F^{*}}\right)=\left\{\frac{\sigma_{1}}{2 b} s_{2}^{F^{*}}, \tilde{s}_{2}^{*}\right\}$ and Firm 1's MVI is $\sigma_{1}<2 b$.

2. A symmetric equilibrium where he offers the same services as Firm 2, given by $s_{1}^{V^{*}}, s_{2}^{F^{*}}\left(s_{1}^{V^{*}}=s_{2}^{*}\right)=\left\{\widetilde{F}_{1}^{V^{*}}, \tilde{s}_{2}^{*}\right\}$ for any MVI of Firm 1.

In order for the service pair $\left\{s_{1}^{V^{*}}, s_{2}^{F^{*}}\right\}$ to be an equilibrium candidate, it is necessary that $\max \left\{\pi_{1}^{\tilde{V}}\left(., s_{2}^{*}\right)\right\}=\pi_{1 a}^{\tilde{V}}\left(s_{1}^{\widetilde{V}^{*}}\right) \quad$ and $\quad \max \left\{\pi_{2}^{\widetilde{F}}\left(s_{1}^{*},.\right)\right\}=\pi_{2 c}^{\widetilde{F}}\left(s_{2}^{\tilde{F}^{*}}\right) \quad$ in $\quad$ case $\quad 1, \quad$ or $\max \left\{\pi_{1}^{\tilde{V}}\left(., s_{2}^{*}\right)\right\}=\pi_{1 b}^{\widetilde{V}}\left(s_{1}^{\tilde{V}^{*}}\right)$ and $\max \left\{\pi_{2}^{\widetilde{F}}\left(s_{1}^{*},.\right)\right\}=\pi_{2 b}^{\widetilde{F}}\left(s_{2}^{F^{*}}\right)$ in case 2. $\quad$ Since it is never optimal for the firm pursuing fixed-services to offer fewer services than the firm pursuing variable-services strategy, the only possible asymmetric equilibrium will be characterized by $s_{1} \widetilde{V}^{*}<s_{2}^{\tilde{F}^{*}}$ when $\sigma_{1}<2 b$

LEMmA 4. In the subgame where one firm pursues a fixed-services strategy while the other pursues a variable-services strategy, there exists an asymmetric equilibrium given by $\left(s_{1}^{V^{*}}, s_{2}^{F^{*}}\right)=\left(\frac{b \sigma_{1} \sigma_{2}}{4 b\left(b+\sigma_{2}\right)+\sigma_{1} \sigma_{2}}, \frac{2 b^{2} \sigma_{2}}{4 b\left(b+\sigma_{2}\right)+\sigma_{1} \sigma_{2}}\right)$, when $\quad \sigma_{1} \in\left[0, \frac{2 b}{1+\sqrt{2}}\right)$ and $\sigma_{2} \in\left[\frac{8 b^{2} \sigma_{1}}{4 b^{2}-4 b \sigma_{1}-\sigma_{1}^{2}}, \infty\right)$

\subsection{Subgame-perfect Nash Equilibria (SPNE) for the full game}

Having characterized the equilibria for the second stage subgame, we now proceed to determine the SPNEs for the full game. Note that similar to a traditional price-location game where price and location are the two strategic variables, the two strategic variables available to the firms here are their choices regarding fixed- versus variable-services and the actual number of services offered. However, note that the MVI-related conditions from within the possible subgame equilibria tell us about the relative valuations of the firms that allow for an equilibrium to exist. In verifying that any or all of the second-stage equilibria are subgame-perfect, we need not only to consider the strategies and service space, but also the bounds within which these are valid.

PROPOSITION 1. When one firm has a low marginal value for information and the other firm has a slightly higher value, then there exists a unique SPNE in pure strategies where both firms offer fixed-services and segment the market. As the difference in the valuations between the two firms increases, a second SPNE in pure strategies exists. The low MVI firm can now also consider a variable-services strategy while maintaining the same service levels and profits. 
Proposition 1 characterizes competition when firms are small but differentiated in their marginal value for information. Note that throughout this paper, for the sake of exposition we shall use the terms small (large) firm when the firm's MVI is smaller (larger) than a threshold of $2 b$. When firms are sufficiently differentiated in their marginal values for information and if one firm has a low MVI, then the two firms will share the marketplace in such a way that the low MVI firm mainly caters to privacy-seekers and the high MVI firm caters to convenience seekers. Note that when both firms offer fixed-services, the NFD nature of the good does not come into play; i.e., it does not matter what the ideal points are, consumers will select a service-level as long as their individual rationality (IR) constraints are satisfied, and their choice of firm will depend on the individual's incentive compatibility (IC) constraint. We also know that for a given service level, utilities are increasing in the p4p ratio as they satisfy the Spence-Mireeles crossing property, i.e., $u\left(s, p_{a}, r_{a}\right)>u\left(s, p_{b}, r_{b}\right)$ if $\left(\frac{p}{r}\right)_{a}>\left(\frac{p}{r}\right)_{b}$. Given this regularity condition, it is not surprising that we observe a separating equilibrium as in other models, such as in vertically segmented markets for goods with free disposal where one firm serves the low types and the other serves the high types (Moorthy 1988). The condition on the separation of MVIs essentially ensures that the firm with low MVI will not attempt to undercut the higher MVI competitor due to the tradeoff between its costs and marginal value for information.

However, note that when the differentiation between the two firms is high then the low MVI firm also has the option of employing variable services without affecting the strategy of the competitor. The intuition behind this is that by offering variable services, the low MVI firm is essentially serving those consumers who would have been left un-served when both firms offered fixedservices i.e., those with very low $\mathrm{p} 4 \mathrm{p}$ ratios $\left(s_{c}^{0}<s_{1}^{F^{*}}\right)$. At the same time the firm loses some of the surplus that it could have extracted from some consumers whose optimal service level was less than $s_{1}^{F^{*}}$, as these consumers now only use their respective $s_{c}^{*}$. However, since the equilibrium service level and the profits are same when the low MVI firm pursues this strategy, both equilibria are SPNE.

An important result to note is that in equilibrium, whenever at least one firm offers variable services, the market will always be fully covered and the consumer surplus will always be higher (compared to that when both firms offer fixed-services). The simple intuition behind this is that whenever one firm allows consumers to choose their desired service level, every consumer can find a service level that corresponds to a non-zero utility; while low types (privacy-seekers) will pick up some service level lower than that offered by the variable-services firm, the high types (convenience-seekers) will choose between this firm and the competitor who offers a higher service level. Thus from a consumer surplus point of view even if one firm offers variable-services, consumers are always better off. 
PROPOSITION 2. The competition between firms with high marginal value for information is characterized by unique symmetric SPNE in pure strategies.

a) Both firms employ a fixed-services strategy if both their marginal valuation for information is large but within a threshold value $(10 b)$. One-third of the market defined by privacy seekers will be left out in this equilibrium.

b) When one or both firms exceed the marginal valuation for information given by the threshold value in (a), then both firms employ a variable-services strategy. The market is fully covered in this equilibrium.

Proposition 2 tells us that firms with high MVI (but close to 2b) will both choose the fixed-services strategy, offer the same level of services $\frac{b}{3}$ and share the market. Note that even if some consumers prefer more services $\left[s_{c}^{*} \in\left[\frac{b}{3}, \frac{b}{2}\right]\right)$ and the marginal costs of versioning and serving an additional consumer is zero, when MVIs of both firms are within the $10 b$ threshold, they prefer to maintain a fixed-services strategy and offer less than the maximum level of preferred services. The economic intuition behind this finding stems both from the capacity cost constraint and the market size that can be served: given that firms choose fixed-services strategy in stage 1 , the surplus that they can extract from each participating consumer is the same; hence the focus of their strategic choices of the service level in the second stage is to increase their market shares. By offering a service level higher than $\frac{b}{3}$ would make a firm attractive to consumers with high $\frac{p}{r}$ ratio $\left(\right.$ those with $\left.s_{c}^{*} \in\left[s, \frac{b}{2}\right]\right)$, while the remaining consumers $\left(\right.$ those with $\left.s_{c}^{*} \in\left[\frac{b}{3}, s\right)\right)$ might begin to prefer the competitor. In addition, the vendor also has to incur increased cost of producing above this level. Essentially, gain from more convenience-seeker's usage of services does not outweigh loss (from both the increased cost and loss of some privacy-seekers to the competitor) from offering services above this equilibrium level. So in attempting to tradeoff these gains and losses, both firms end up serving and sharing the upper two-thirds of the market and leaving the rest (consumers with $s_{c}^{0}<\frac{b}{3}$ ) uncovered.

The implication of this result is that even if the marginal cost of serving an additional consumer is zero, the competitive dynamics of a fixed-services approach will lead firms to maximize profits by not serving the segment of consumers with minimal value for personalization and/or high privacy concerns. At the same time some consumers $\left(\frac{b}{3}<s_{c}^{*} \leq \frac{b}{2}\right)$ are left wanting for more services, as the equilibrium service level will not fully satisfy this segment. An important reason as to why firms need to possess sufficiently high MVIs for the symmetric equilibrium to exist is that when one firm is below the threshold, there is always the tendency for firms to serve different portions of the market as posited in Proposition 1 . On the other hand, two small firms 
never find it optimal to share the market. The simple intuition is that since consumers are indifferent between the services offered by the two firms as long as they offer the same level of services, both firms incur the full infrastructure costs while only getting half the market and firms could always increase this market size by offering slightly more or fewer number of services.

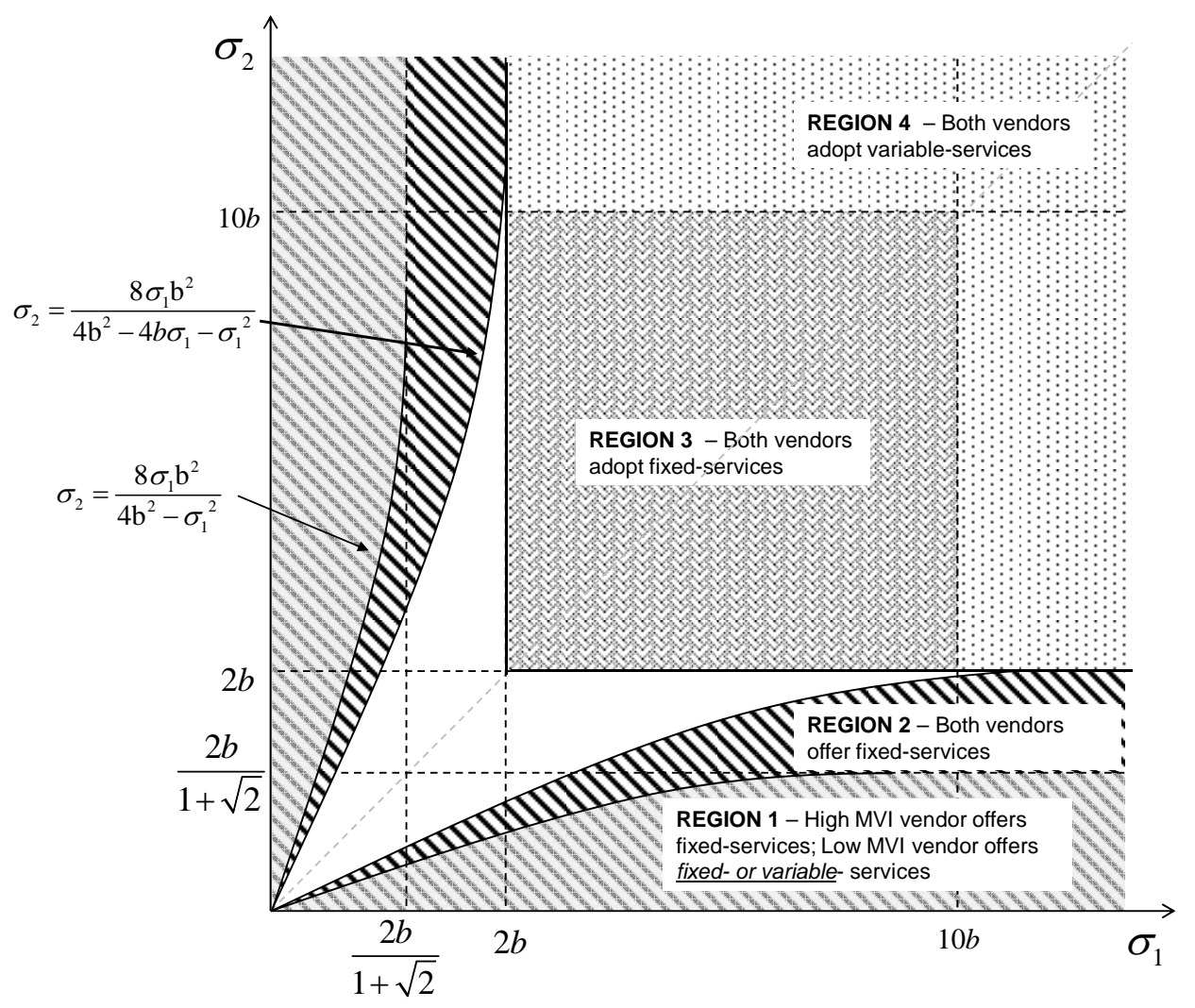

Figure 4: SPNE regions

The case defined by part $b$ of Proposition 2 is unique to our model in that it is characterized by the NFD property of personalization services, as well as the zero marginal and versioning costs of offering variable services. The intuition behind this part is as follows: since consumers are indifferent between the two firms and are free to choose their individual desired levels of personalized services, if two firms offer different service levels, then the firm offering a higher service level would get half of market of its competitor while further capturing the entire segment of consumers whose personalization needs are higher than the competitor's offering (i.e. consumers with $\left.s_{c}^{*} \in\left[\min \left\{s_{1}, s_{2}\right\}, \max \left\{s_{1}, s_{2}\right\}\right]\right)$. While offering more services than the competitor appears preferable, because no consumer has $s_{c}^{*}$ greater than $\frac{b}{2}$, no firm would offer services higher than this level. Hence, if the MVIs are high enough for firms to offset the cost of offering such a high level of personalization, both firms would offer the maximum level of services desired by the consumers in equilibrium. Thus the equilibrium service level is independent of the firms' own MVIs (as long as they are above the threshold), and all consumers enjoy their ideal level of personalization services. Intuitively, it might appear that firms would prefer to set a specific service level and require consumers to use that prescribed level, 
consistent with price setting behavior in most markets. However, in our context of zero marginal and versioning costs and lack of any separate instrument such as price, the results indicate that at times, the best competitive strategy is to serve the market at the consumers' preferred level.

Figure 4 characterizes the region of competition between firms of different types (varying in their marginal value for information) where SPNE exists in pure strategies. In Table 1 below, we provide a summary of all the SPNE strategies and profits as discussed in Propositions 1 and 2. Note that firm types refer to the various characterizations of duopolies as defined by their respective marginal value for information. Also note from Figure 4, there is a region describing the competitive markets where no pure-strategy equilibrium exists. This suggests that for a duopoly characterized by firm types in this region, the firms might continue to undercut each other by offering services that are perhaps not optimal. There may be a possibility of mixed-strategy equilibria in this space where firms of these types might randomize their services strategies.

Table 1: SPNE strategies and profits for different duopolies

\begin{tabular}{|c|c|c|}
\hline Firm Types & Strategies & Profits \\
\hline $\begin{array}{c}\text { Two equilibria } \\
\text { (Region } 1 \text { in Figure 4) } \\
\sigma_{1} \in\left[0, \frac{2 b}{1+\sqrt{2}}\right) \\
\sigma_{2} \in\left[\frac{8 \sigma_{1} \mathrm{~b}^{2}}{4 \mathrm{~b}^{2}-4 b \sigma_{1}-\sigma_{1}^{2}},+\infty\right)\end{array}$ & $\begin{array}{l}\left(s_{1}^{F}, \frac{\mathrm{b} \sigma_{1} \sigma_{2}}{4 \mathrm{~b}\left(\mathrm{~b}+\sigma_{2}\right)+\sigma_{1} \sigma_{2}}\right) \\
\left(s_{2}^{F}, \frac{2 \mathrm{~b}^{2} \sigma_{2}}{4 \mathrm{~b}\left(\mathrm{~b}+\sigma_{2}\right)+\sigma_{1} \sigma_{2}}\right) \\
\left(s_{1}^{V}, \frac{\mathrm{b} \sigma_{1} \sigma_{2}}{4 \mathrm{~b}\left(\mathrm{~b}+\sigma_{2}\right)+\sigma_{1} \sigma_{2}}\right) \\
\left(s_{2}^{F}, \frac{2 \mathrm{~b}^{2} \sigma_{2}}{4 \mathrm{~b}\left(\mathrm{~b}+\sigma_{2}\right)+\sigma_{1} \sigma_{2}}\right)\end{array}$ & $\begin{array}{c}\pi_{1}^{F^{*}}=\pi_{1}^{V^{*}} \\
=\frac{b^{2} \sigma_{1}^{2} \sigma_{2}^{2}}{\left[4 b\left(b+\sigma_{2}\right)+\sigma_{1} \sigma_{2}\right]^{2}} \\
\pi_{2}^{F^{*}}=\frac{4 b^{3} \sigma_{2}^{2}\left(b+\sigma_{2}\right)}{\left[4 b\left(b+\sigma_{2}\right)+\sigma_{1} \sigma_{2}\right]^{2}}\end{array}$ \\
\hline $\begin{array}{c}\text { Unique Equilibrium: } \\
\text { (Region } 2 \text { in Figure 4) } \\
\sigma_{1} \in[0,2 b) \\
\sigma_{2} \in\left[\frac{8 \sigma_{1} \mathrm{~b}^{2}}{4 \mathrm{~b}^{2}-\sigma_{1}^{2}}, \frac{8 \sigma_{1} \mathrm{~b}^{2}}{4 \mathrm{~b}^{2}-4 b \sigma_{1}-\sigma_{1}^{2}}\right)\end{array}$ & $\begin{array}{l}\left(s_{1}^{F}, \frac{\mathrm{b} \sigma_{1} \sigma_{2}}{4 \mathrm{~b}\left(\mathrm{~b}+\sigma_{2}\right)+\sigma_{1} \sigma_{2}}\right) \\
\left(s_{2}^{F}, \frac{2 \mathrm{~b}^{2} \sigma_{2}}{4 \mathrm{~b}\left(\mathrm{~b}+\sigma_{2}\right)+\sigma_{1} \sigma_{2}}\right)\end{array}$ & $\begin{array}{l}\pi_{1}^{F^{*}}=\frac{b^{2} \sigma_{1}^{2} \sigma_{2}^{2}}{\left[4 b\left(b+\sigma_{2}\right)+\sigma_{1} \sigma_{2}\right]^{2}} \\
\pi_{2}^{F^{*}}=\frac{4 b^{3} \sigma_{2}^{2}\left(b+\sigma_{2}\right)}{\left[4 b\left(b+\sigma_{2}\right)+\sigma_{1} \sigma_{2}\right]^{2}}\end{array}$ \\
\hline $\begin{array}{c}\text { Unique Equilibrium: } \\
\text { (Region } 3 \text { in Figure } 4 \text { ) } \\
\sigma_{i} \in[2 b, 10 b), i \in\{1,2\}\end{array}$ & $\left\{\left(s_{1}^{F}, \frac{b}{3}\right) ;\left(s_{2}^{F}, \frac{b}{3}\right)\right\}$ & $\begin{array}{l}\pi_{1}^{F^{*}}=\frac{b\left(\sigma_{1}-b\right)}{9} \\
\pi_{2}^{F^{*}}=\frac{b\left(\sigma_{2}-b\right)}{9}\end{array}$ \\
\hline $\begin{array}{c}\begin{array}{c}\text { Unique Equilibrium: } \\
\text { (Region } 4 \text { in Figure 4) }\end{array} \\
\sigma_{i} \in[10 b,+\infty), i \in\{1,2\}\end{array}$ & $\left\{\left(s_{1}^{V}, \frac{b}{2}\right) ;\left(s_{2}^{V}, \frac{b}{2}\right)\right\}$ & $\begin{aligned} \pi_{1}^{V^{*}} & =\frac{b\left(\sigma_{1}-2 b\right)}{8} \\
\pi_{2}^{V^{*}} & =\frac{b\left(\sigma_{2}-2 b\right)}{8}\end{aligned}$ \\
\hline
\end{tabular}




\subsection{Welfare analyses}

Welfare analysis is an important part of any research on privacy, for the simple reason that many of rules and regulations governing consumers' online privacy concerns are the domain of regulatory bodies. So in our research we are interested in not only the competitive outcomes but also in the resulting consumer and social welfare. In this sub-section we examine welfare under the different SPNE to provide managerial and regulatory recommendations.

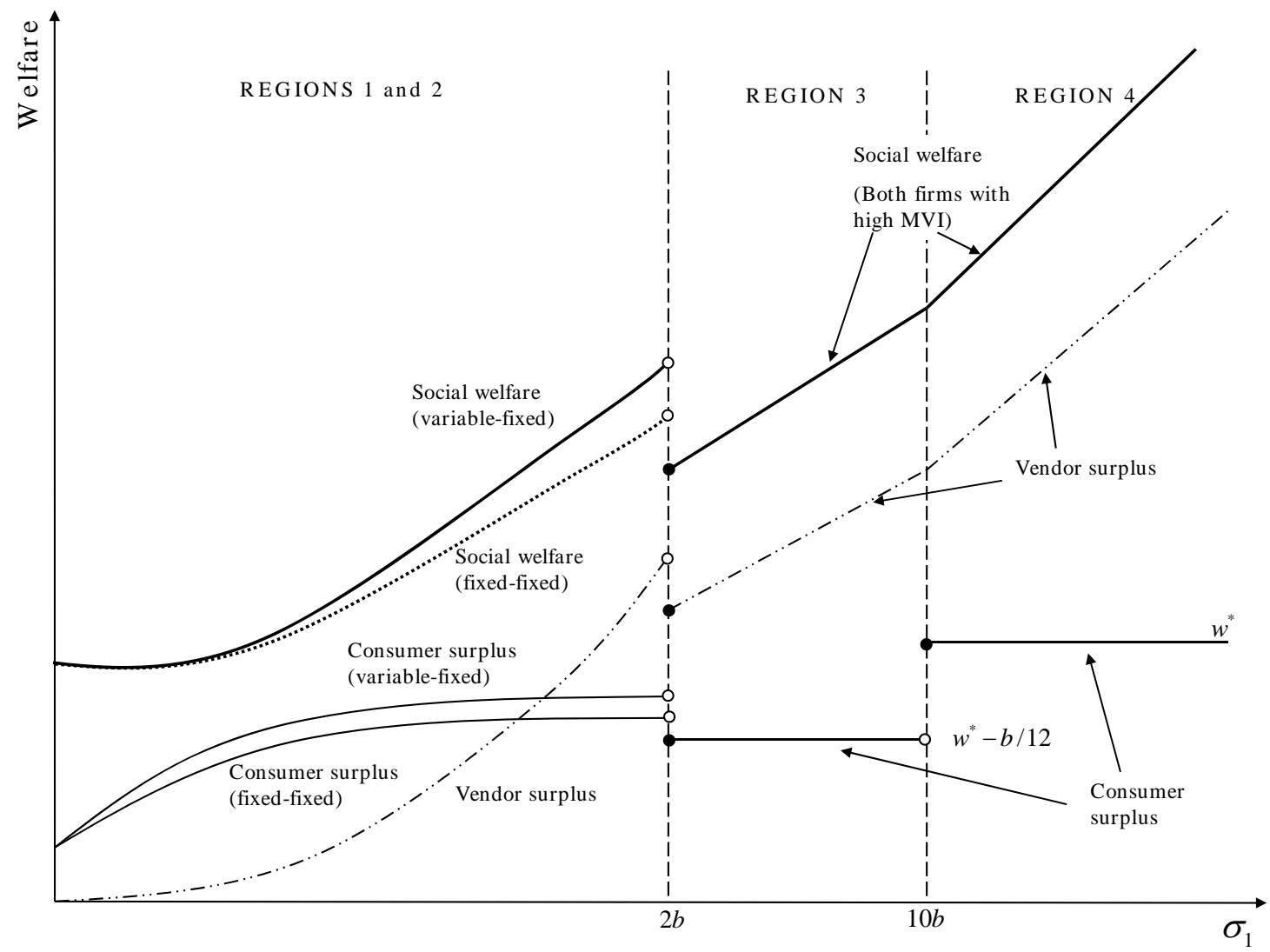

Figure 5: Welfare comparison: both firms offering fixed- versus variable-services strategy

PROPOSITION 3. Consumer welfare is generally increasing in the firms' marginal value for information and provision of variable-services (instead of fixed) even by one firm always improves consumer welfare. However, under certain conditions consumers and society are better off when firms are sufficiently differentiated and serve different portions of the market than when then there is a fixed-services symmetric equilibrium. Consumer and social welfare is maximized in the case of competition between two firms with 
It is intuitive to see that consumer surplus is always higher when variable services are offered even by one firm for two reasons: First, under variable services consumers get to pick their service levels and they will choose their surplus maximizing service levels as long is available. Second, no consumer is left behind (even if some may have to compromise with using less than their optimal level of services). The welfare implications from fixed-services equilibria, however, are not as straight-forward. When one firm is small, the market results in an asymmetric equilibrium where both firms pursue fixed-services strategy such that they segment the market where the convenience seekers and privacy seekers are served by the high and the low MVI firm respectively (and where some high privacy seekers are left un-served). From the comparative statics, it is interesting to observe that as the marginal value for information of the low MVI firm $\left(\sigma_{1}\right)$ is increasing (the differentiation between the two firms is decreasing), both the consumer surplus and social welfare are increasing in $\sigma_{1}$ to a point (see Figure 5). However, when $\sigma_{1}$ crosses the $2 b$ threshold, the asymmetric equilibrium is no longer feasible and both firms prefer to offer the same service level and share the market equally rather than segmenting them. In such a case, the consumer surplus and social welfare drop to a level less than those when the marginal value for information of the low MVI firm is high enough but not enough to force a symmetric strategy from the high MVI firm. The economic intuition behind this observation is that when the MVI of the smaller firm is increasing in the asymmetric case, the larger firm moves the left (decreases it service offering) but still both firms serve two distinct segments of the market. More ever since the service level offered by the smaller firm is less than $\frac{b}{3}$, the market served under the asymmetric case is always higher than when both firms offer the same fixed-services. When the MVI of the smaller firm crosses the threshold not only do both firms together serve only two-thirds of the market but they each incur the entire cost of the infrastructure as well. Thus both consumer and social welfare is lower when two large firms compete to result in a fixed-services equilibrium.

This state remains till at least one firm is large enough to find it optimal to serve the entire market at each consumer's optimal service level (variable-services at $\frac{b}{2}$ ). In this case, the second firm has no other option but to offer the same variableservice level thus moving consumer welfare to its highest. Such a solution is pareto optimal, and is the competitive equilibrium outcome when both firms have a marginal value for information above $10 b$. The 4 regions depicted in Figure 5 can be understood as 3 different market conditions; while regions 1 and 2 are perhaps representative of a nascent market where not all firms have figured out how to use consumer information effectively, region 4 represents the case where firms have fully matured in this capability. We have summarized these welfare findings in Table 2 below.

Table 2: Welfare under different models of firm competition

\begin{tabular}{c|c}
$\begin{array}{c}\text { Type of } \\
\text { Competition }\end{array}$ & Equilibrium Welfare \\
\hline
\end{tabular}




\begin{tabular}{|c|c|}
\hline $\begin{array}{l}\text { High and low MVI firms } \\
\text { (both firms adopt fixed- } \\
\text { services strategy) }\end{array}$ & $\begin{array}{l}\text { Consumer surplus }=w^{*}-\frac{b\left(16 b^{4}-8 b \sigma_{1} \sigma_{2}{ }^{2}+5 \sigma_{1}{ }^{2} \sigma_{2}{ }^{2}+8 b^{2} \sigma_{2}\left(\sigma_{1}+\sigma_{2}\right)\right)}{4\left(4 b^{2}+4 b \sigma_{2}+\sigma_{1} \sigma_{2}\right)^{2}} \\
\text { Social welfare } \\
= \\
w^{*}-\frac{b\left(5 \sigma_{1}^{2} \sigma_{2}^{2}+16 b^{4}-16 b^{3} \sigma_{2}^{2}-4 b \sigma_{1} \sigma_{2}{ }^{2}\left(2+\sigma_{1}\right)+8 b^{2} \sigma_{2}\left(\sigma_{1}+\sigma_{2}-2 \sigma_{2}{ }^{2}\right.\right.}{4\left(4 b^{2}+4 b \sigma_{2}+\sigma_{1} \sigma_{2}\right)^{2}}\end{array}$ \\
\hline $\begin{array}{l}\text { High and low MVI firms } \\
\text { (high MVI firm adopts fixed- } \\
\text { services and low MVI firm } \\
\text { adopts variable services } \\
\text { strategy) }\end{array}$ & $\begin{array}{l}\text { Consumer surplus }=w^{*}-\frac{b\left(16 b^{4}-8 b \sigma_{1} \sigma_{2}{ }^{2}+3 \sigma_{1}{ }^{2} \sigma_{2}{ }^{2}+8 b^{2} \sigma_{2}\left(\sigma_{1}+\sigma_{2}\right)\right)}{4\left(4 b^{2}+4 b \sigma_{2}+\sigma_{1} \sigma_{2}\right)^{2}} \\
\text { Social welfare } \\
= \\
w^{*}-\frac{b\left(3 \sigma_{1}{ }^{2} \sigma_{2}{ }^{2}+16 b^{4}-16 b^{3}{\sigma_{2}}^{2}-4 b \sigma_{1} \sigma_{2}{ }^{2}\left(2+\sigma_{1}\right)+8 b^{2} \sigma_{2}\left(\sigma_{1}+\sigma_{2}-2 \sigma_{2}{ }^{2}\right.\right.}{4\left(4 b^{2}+4 b \sigma_{2}+\sigma_{1} \sigma_{2}\right)^{2}}\end{array}$ \\
\hline $\begin{array}{l}\text { High MVI firms } \\
\text { (both firms adopt fixed- } \\
\text { services strategy) }\end{array}$ & $\begin{array}{l}\text { Consumer surplus }=w^{*}-\frac{b}{12} \\
\text { Social welfare }=w^{*}-\frac{8 b^{2}-b\left(4\left(\sigma_{1}+\sigma_{2}\right)-3\right)}{36}\end{array}$ \\
\hline $\begin{array}{l}\text { High MVI firms where the } \\
\text { MVI of at least one firm } \\
\text { exceeds } 10 b \\
\text { (both firms adopt variable- } \\
\text { services strategy) }\end{array}$ & $\begin{array}{l}\text { Consumer surplus }=w^{*} \\
\text { Social welfare }=w^{*}-\frac{4 b^{2}-b\left(\sigma_{1}+\sigma_{2}\right)}{8}\end{array}$ \\
\hline
\end{tabular}

\section{Managerial and policy implications}

An important motivation for our problem is the emergence of new browser-embedded technologies such as toolbars that provide firms with greater control over how information about consumers' online usage is acquired. The fixed-services strategy - the option to acquire a fixed-amount of information and deliver a given set of personalized services - was hitherto non-existent as early forms of personalization was largely restricted to user controlled Web-based static mechanisms. For example, personalization through a Web interface relies largely on server logs and cookies and it is difficult for a firm to require consumers to use all services offered. Due to the static nature of the Web's Hyper Text Transfer Protocol (HTTP), the most control that firms enjoyed was that they could "expire" accounts that did not use enough services or share adequate information. It is in fact the fixed-services contract that a user agrees to, often with little or no control subsequently, that has gotten the attention of the media and privacy groups that compare these toolbars to spyware technologies (e.g., the recent campaign against Ask Jeeves (Stone 2005)). It is indeed this potentially detrimental level of control over how much users share and what they get the main subject of ongoing FTC investigations into the legitimate and illegitimate uses of toolbar-like technologies (FTC 2004). 
While many spurious firms are employing toolbars giving rise to their "Spyware" reputation, numerous legitimate online firms are employing the same technologies for personalizing services to their users due to its non-intrusive nature. Currently, large firms like Yahoo! and MSN offer all of their personalization services (more than those available through their Web-based technologies) through browser-embedded toolbars. Their strategy so far has been to allow consumers to select a subset of their toolbar services. For example, Google provides a toolbar wherein one could personalize search, mail, and a variety of other services including a feature called PageRank that is considered to be highly intrusive by many. However, Google provides users with the option of using only a subset of its toolbar-based personalization, allowing users to turn-off the PageRank option and thus not collecting the associated information. This is in contrast to strategies of those in the retail space such as Amazon with its Alexa and A9.com toolbars, where Amazon does not allow consumers to choose a subset of services to personalize. Once a user downloads and embeds the A9.com toolbar, a variety of information including the Web-sites visited, products searched for, email addresses used in fill-in forms, etc., is automatically acquired and the user is then provided with a personalized list of sites and products during next usage; although currently the toolbar focuses only on products carried by its parent company, Amazon.com. The user has no control in that she cannot specify that the A9 toolbar should collect and report information (and hence personalize) only on certain services but not others.

From a managerial perspective, since firms' profits are increasing in consumers' p4p ratio, our results suggest that firms should employ significant trust building and other reassuring services that are known to help allay privacy concerns and therefore increase the $\mathrm{p} 4 \mathrm{p}$ ratios. Since firms with large MVIs will have a strong incentive to move towards variable-services offering, it is evident that smaller independent firms that solely depend on external agencies such as DoubleClick for generating value from information will find it hard to continue sustaining in this market. Perhaps these smaller firms will distinguish themselves by going the niche services route or will be absorbed into some larger firms. It is also interesting to note that while in the highly competitive marketplace firms offer variable toolbar-sizes, Amazon is currently persisting with the fixed-services approach. This could perhaps be attributed to its near monopoly status in the area of retail personalization, although our model would suggest that with increasing number of firms occupying this space, Amazon will eventually allow consumers the option to choose a subset of its A9.com toolbar services.

\subsection{Policy implications}

Our results suggest that consumer welfare is increasing the firms' ability to use information, i.e., when they value a unit of information more. Our results suggest that when a market is mature with firms already having figured out effective usage of customer information, the competitive dynamics dictate that the firms offer the maximum possible number of services that the market would consume at each consumers' preferred level. This is perhaps the best situation a regulator can hope for where market competition is actually consumer welfare maximizing. 
There could potentially be two responses to addressing the concerns of privacy advocates. One that bars information acquisition itself and a second that bars the usage of the information acquired. Our findings suggest that if the regulator can encourage the effective use of information by firms (such they are able to increase their marginal value for information) there is then no need prevent information acquisition since competition will ensure that firms act in fashion that is favorable to the consumer. Indeed it is only in nascent markets with small firms where the fixed-services strategy (and its allied use of restrictive toolbar-type technologies) is in use. On the other hand it is clear that the regulator should play an important role in preserving the sanctity of contracts entered into by the consumer and firm. Since the consumers' privacy concern is based on some expectation of how their information will be used it is important that the consumer is both made aware and educated on this dimension.

One other suggestion might be to allow for ongoing consolidations in the firm space where many firms are beginning to merge, thus reducing the number of smaller independent firms to a few large ones. For example, Yahoo! now owns Inktomi, Overture, and Altavista; Lycos has acquired or merged with Tripod, Angelfire, Matchmaker and Wired; InfoSpace now includes Dogpile, WebCrawler, MetaCrawler and WebFetch. This is perhaps one of those unique markets where an oligopoly of a few large players might be beneficial to the consumers. Through variable-services offerings large firms also end up serving those consumers in the fringe of the market (i.e., highly privacy-sensitive consumers).

\subsection{Implications to theory}

From a modeling point of view, our research adds to the literature on competition in NFD goods and services markets; and from a theoretical perspective, the competition is characterized by discontinuous payoffs that generally suggest existence of equilibrium only in mixed-strategies (Dasgupta and Maskin 1986) while we are able to derive SPNE in pure strategies. The NFD aspect of the good combined with the zero-marginal and zero-versioning costs have a pronounced effect when the market is characterized by variableservices offering. Unlike in the fixed-services case where non-zero utility was the main participation criteria, in the variable-services case consumers select services based on how far they are from their ideal-points (the surplus-maximizing level) and many consumers may be satisfied at their desired levels. The closest physical world examples can be found in models of franchise competition where fast-food franchises and car dealerships can locate themselves at multiple points on a linear market (Hadfield 1991; lyer 1998). Our results show that such a market is only characterized by symmetric, consumer-surplus maximizing equilibria in a duopoly of high MVI firms. From a modeling perspective, this draws comparisons with outside location games where firms place themselves on the edge of a linear market and maximize welfare (Gabszewicz and Thisse 1992).

\subsection{Limitations and future research}

As with any first model of a real-world context, we are limited in the number of issues we can explore in the current paper. One first such limitation is perhaps the assumption that firms only vary in their MVI and have common cost coefficients. It is quite 
possible that firms may also differ in their ability to personalize and also in the liability costs of the information they acquire, process and store. Further, we have assumed a simple personalization technology here where a unit of personalized service can be generated for a given unit of personal information; with rapid advances in technology perhaps more services can be produced for a single unit of information. Indeed, it would be interesting to explore how firms can differentiate themselves on the basis of the amount of services they can offer for a single piece of information rather than only the total number of indistinguishable services. Another interesting extension to our model would be the possibility of offering incentives along with information acquisition services and develop services-incentive menus for NFD goods and services. 
References

Anonymous. 2001. HIPPA Privacy Rule Takes Effect. Healthcare Financial Management 55(6) 9.

Baye, M. R., G. Tian and J. Zhou. 1993. Characterizations of the Existence of Equilibria in Games with Discontinuous and Nonquasiconcave Payoffs. Review of Economic Studies 60 935-948.

Bloom, P. N., G. R. Milne and R. Adler. 1994. Avoiding Misuse of New Information Technologies: Legal and Societal Considerations. Journal of Marketing 58(1) 98-110.

Chellappa, R. K. and S. Shivendu. 2006. A Model of Advertiser - Portal Contracts: Personalization Strategies under Privacy Concerns. Information Technology and Management 7(1) 7-19.

Chellappa, R. K. and S. Shivendu. 2007. An Economic Model of Privacy: A Property Rights Approach to Regulatory Choices for Online Personalization. Journal of Management Information Systems 24(3) 193-226.

Chellappa, R. K. and S. Shivendu. 2008. Mechanism Design for "Free" but "No Free Disposal" Services: The Economics of Personalization under Privacy Concerns. working paper.

Chellappa, R. K. and R. Sin. 2005. Personalization versus Privacy: An Empirical Examination of the Online Consumer's Dilemma. Information Technology and Management 6(2-3) 181-202.

Culnan, M. J. and R. J. Bies. 2003. Consumer Privacy: Balancing Economic and Justice Considerations. Journal of Social Issues 59(2) 104-115.

D'Aspremont, C., J. J. Gabszewicz and J.-F. Thisse. 1979. On Hotelling's "Stability in Competition". Econometrica 47(5) 1145-1150.

Dasgupta, P. and E. Maskin. 1986. The Existence of Equilibrium in Discontinuous Economic Games, I: Theory. The Review of Economic Studies 53(1) 1-26.

Derlega, V., S. Metts, S. Petronio and S. Margulis. 1993. Self-Disclosure.

Desai, P. 2001. Quality Segmentation in Spatial Markets: When Does Cannibalization Affect Product Line Design? Marketing Science 20(3) 265-283.

Dewan, R., M. Freimer and A. Seidmann. 1999. Portal Kombat: The Battle between Web Pages to become the Point of Entry to the World Wide Web. Thirty Second Annual Hawaii International Conference on System Sciences, Maui, HI.

Economides, N. 1984. The Principle of Minimum Differentiation Revisited. European Economic Review 24 345-368.

Essegaier, S., S. Gupta and Z. J. Zhang. 2002. Pricing Access Services. Marketing Science 21(2) 139-159.

FTC. 2003. Information Flows: The Costs and Benefits to Consumers and Businesses of The Collection and Use of Consumer Information. Federal Trade Commission Workshop June 18, Washington DC.

FTC. 2004. Monitoring Software on Your Pc: Spyware, Adware, and Other Software. Federal Trade Commission Workshop \#110 Project P044509 Washington DC.

Gabszewicz, J. J. and J.-F. Thisse. 1986. On the Nature of Competition with Differentiated Products. The Economics Journal 96(381) 160-172. 
Gabszewicz, J. J. and J.-F. Thisse. 1992. Location. Handbook of Game Theory. R. J. Aumann and S. Hart. Elsevier Science Publishers. 1: $281-304$.

Hadfield, G. K. 1991. Credible Spatial Preemption through Franchising. The RAND Journal of Economics 22(4) 531-543.

Hotelling, H. 1929. Stability in Competition. Economic Journa/ 39 41-57.

Iyer, G. 1998. Coordinating Channels under Price and Nonprice Competition. Marketing Science 17(4) 338-355.

Laufer, R. S. and M. Wolfe. 1977. Privacy as a Concept and a Social Issue: A Multidimensional Developmental Theory. Social Issues $33(3) 22-24$.

Milgrom, P. and J. Roberts. 1994. Comparing Equilibria. American Economic Review 84(3) 441-459.

Moorthy, K. S. 1985. Using Game Theory to Model Competition. Journal of Marketing Research 22(3) $262-282$.

Moorthy, K. S. 1988. Product and Price Competition in a Duopoly. Marketing Science 7(2) 141-156.

Murthi, B. P. S. and S. Sarkar. 2003. The Role of the Management Sciences in Research on Personalization. Management Science 49(10) $1344-1362$.

Nahata, B., S. Kokovin and E. Zhelobodko. 2003. Package Sizes, Tariffs, Quantity Discount and Premium. Economics Working Paper Archive at WUSTL 35.

Rothwell, G. and J. Rust. 1997. On the Optimal Lifetime of Nuclear Power Plants. Journal of Business and Economic Statistics, American Statistical Association 15(2) 195-208.

Rust, R. T., P. K. Kannan and N. Peng. 2002. The customer economics of Internet privacy. Journal of the Academy of Marketing Science 30(4) 455-464.

Salop, S. 1979. Monopolistic Competition with Outside Goods. Bell Journal of Economics 10 141-156.

Scott, J. S. 1999. Privacy, Confidential, and Security: Protecting "Personally Identifiable Information". Healthcare Financial Management 53(3) $26-27$.

Shankar, V., A. K. Smith and A. Rangaswamy. 2003. Customer Satisfaction and Loyalty in Online and Offline Environments. International Journal of Research in Marketing 20(2) 153-175.

Stone, B. 2005. Uneasy Rider: Ask Jeeves didn't ask before installing a search tool on millions of Web browsers. Now investors are asking questions. Newsweek June 03, MSNBC Web exclusive.

Sundararajan, A. 2004. Nonlinear Pricing of Information Goods. Management Science 50(12) 1660-1673.

Varian, H. R. 1997. Versioning Information Goods. Internet Publishing and Beyond: Economics of Digital Information and Intellectual Property. B. Kahin and H. R. Varian. MIT Press, Cambridge, MA: 1-13.

Volokh, E. 2000. Personalization and Privacy. Communications of the ACM 43(8) 84-88. 
Appendix: Proof of Lemmas and Propositions

Part I - Existence of pure-strategy equilibrium

Let $I$ denote the set of players in a non-cooperative game. For each agent $i \in I$, let the strategy set be defined as

$S_{i} \subset \mathbb{R}$. Notice that $S_{i}$ is a closed-interval, non-empty vector with no gap, which implies that the strategy space is convex $\left(s_{i}=\theta x_{i}+(1-\theta) y_{i} \in S_{i} \forall \theta \in[0,1] ; \quad x_{i}, y_{i} \in S_{i}\right) . \quad S_{i} \quad$ is $\quad$ compact $\quad$ because $\quad$ it $\quad$ is $\quad$ both $\quad$ closed $\left(S_{i}=\left\{s_{i} \in S_{i} \mid 0 \leq s_{i} \leq b\right\}\right)$ and bounded $\left(S_{i} \subset \mathbb{R}, \exists r \in \mathbb{R}\right.$ such that $\left.\left\|s_{i}\right\|<r \forall s_{i} \in S_{i}\right)$. Further, let $S$ be the Cartesian product $\Pi_{i \in I} S_{i}$. The payoff function of each agent is $\pi_{i}: S \rightarrow \mathbb{R}$. Using the notation of Baye et al. (1993), the aggregator function $\Phi: S \times S \rightarrow \mathbb{R} \cup\{ \pm \infty\}$ is given by:

$$
\Phi(x, y)=\sum_{i \in I} \pi_{i}\left(x_{i}, y_{-i}\right)
$$

where $x, y \in S$ and $x_{i} \in S_{i}, y_{-i} \in S_{-i}$. In this proof, we shall show that our aggregator function satisfies the diagonal transfer quasiconcavity (d.t.q.) and diagonal transfer continuity (d.t.c.) conditions that warrant the existence of pure-strategy equilibrium even when the payoff functions are discontinuous (Baye et al. 1993).

Let $A_{i}, B_{i}$ and $C_{i}$ be three non-empty subsets of $S_{i}$ that denote the different sets of strategies that player $i$ may adopt. In particular:

$$
\begin{aligned}
& A_{i}=\left\{s_{i} \in S_{i} \mid s_{i}<s_{-i}, \forall s_{-i} \in S_{-i}\right\} \\
& B_{i}=\left\{s_{i} \in S_{i} \mid s_{i}=s_{-i}, \forall s_{-i} \in S_{-i}\right\} \\
& C_{i}=\left\{s_{i} \in S_{i} \mid s_{i}>s_{-i}, \forall s_{-i} \in S_{-i}\right\}
\end{aligned}
$$

represent the subset of services that belong to regions a, b, and $c$ throughout this paper. Hence the aggregator function can be defined by the corresponding service levels of the two firms:

$$
\begin{aligned}
& \Phi(x, y): A_{i} \times C_{-i} \\
& \Phi(y, y): B_{i} \times B_{-i}
\end{aligned}
$$

When both firms offer fixed-services: To show that $\Phi(x, y)=\pi_{i a}+\pi_{-i c}$ is d.t.q. in $x$ and d.t.c., we shall first demonstrate that $\Phi(x, y)$ is concave in $s_{i}$ :

$$
\Phi(x, y)=-\frac{b s_{-i}^{2}+b s_{i}^{2}-\sigma_{i} s_{i} s_{-i}+\sigma_{-i} s_{i} s_{-i}-b \sigma_{-i} s_{-i}+\sigma_{-i} s_{-i}^{2}}{b}
$$


It can be easily verified that the second order condition of $\Phi(x, y)$ w.r.t. $s_{i}$ is negative. Therefore, by proposition 1 in BTZ (Baye et al. 1993), the aggregator function is diagonally transfer quasiconcave in $s_{i}$. Second, notice that $\Phi(x, y)$ is continuous. Therefore, by proposition 2, the aggregator function is also diagonally transfer continuous. By theorem 1 , the game possesses a pure strategy Nash equilibrium. We can similarly show that a Nash equilibrium in pure strategies exist for other cases considered here.

Part II: Proof of Lemmas

Proof of Lemma 1 \& 2: Equilibria when both firms offer fixed-services

The profit function of Firm 1 (and by symmetry, Firm 2) can be expressed as:

$$
\pi_{1}^{F}=\left\{\begin{array}{c}
\pi_{1 a}^{F}=\sigma_{1} s_{1}\left(\frac{s_{2}}{b}\right)-s_{1}^{2} \quad \text { if } \quad\left(s_{1}<s_{2}\right) \\
\pi_{1 b}^{F}=\frac{\sigma_{1} s_{1}\left(b-s_{1}\right)}{2 b}-s_{1}^{2} \quad \text { if } \quad\left(s_{1}=s_{2}\right) \\
\pi_{1 c}^{F}=\frac{\sigma_{1} s_{1}\left(b-s_{1}-s_{2}\right)}{b}-s_{1}^{2} \quad \text { if } \quad\left(s_{1}>s_{2}\right)
\end{array}\right.
$$

(i) Let there be an asymmetric equilibrium given by $\left\{s_{1}^{F^{*}}, s_{2}^{F^{*}}\left(s_{1}^{F^{*}} \neq s_{2}^{F^{*}}\right)\right\}$. Recall that to be an equilibrium strategy, $s_{1}^{F^{*}}$ must maximize $\pi_{1}^{F}\left(s_{1}, s_{2}^{F^{*}}\right)$ not only in the interval $s_{1}<s_{2}$ but on the whole set of $S_{1}$ (and similarly for Firm 2), i.e.

$$
\pi_{1}^{F}\left(s_{1}^{F^{*}}, s_{2}^{F^{*}}\right) \geq \pi_{1}^{F}\left(s_{1}^{F}, s_{2}^{F^{*}}\right) \quad ; \quad \pi_{2}^{F}\left(s_{1}^{F^{*}}, s_{2}^{F^{*}}\right) \geq \pi_{2}^{F}\left(s_{1}^{F^{*}}, s_{2}^{F}\right)
$$

Solving simultaneously the best responses of the two firms in their respective profit regions, we have $\frac{\sigma_{1}}{2 b} s_{2}=\frac{\left(b-s_{1}\right) \sigma_{2}}{2\left(b+\sigma_{2}\right)}$,

which yields:

$$
\left(s_{1}^{F^{*}}, s_{2}^{F^{*}}\right)=\left(\frac{b \sigma_{1} \sigma_{2}}{4 b\left(b+\sigma_{2}\right)+\sigma_{1} \sigma_{2}}, \frac{2 b^{2} \sigma_{2}}{4 b\left(b+\sigma_{2}\right)+\sigma_{1} \sigma_{2}}\right)
$$

Putting (7) into the respective profit functions of the two firms:

$$
\left(\pi_{1}^{F^{*}}, \pi_{2}^{F^{*}}\right)=\left(\frac{b^{2} \sigma_{1}^{2} \sigma_{2}^{2}}{\left[4 b\left(b+\sigma_{2}\right)+\sigma_{1} \sigma_{2}\right]^{2}}, \frac{4 b^{3} \sigma_{2}^{2}\left(b+\sigma_{2}\right)}{\left[4 b\left(b+\sigma_{2}\right)+\sigma_{1} \sigma_{2}\right]^{2}}\right)
$$

To identify conditions for which (6) is true, we breakdown the necessary conditions as:

$$
\pi_{1 a}^{F}\left(s_{1}^{F^{*}}, s_{2}^{F^{*}}\right) \geq \pi_{1 b}^{F}\left(s_{1}^{F}=s_{2}^{F^{*}}\right)
$$


and

$$
\pi_{1 a}^{F}\left(s_{1}^{F^{*}}, s_{2}^{F^{*}}\right) \geq \pi_{1 c}^{F}\left(s_{1}^{F}>s_{2}^{F^{*}}\right)
$$

for Firm 1. Incorporating the equilibrium services in Firm 1's profit functions and simplifying (9), we have $\frac{2 b^{3} \sigma_{2}\left(2 b \sigma_{2}-2 b \sigma_{1}-\sigma_{1} \sigma_{2}\right)}{\left(4 b^{2}+4 b \sigma_{2}+\sigma_{1} \sigma_{2}\right)^{2}} \geq 0$. This implies $\sigma_{2} \geq \frac{2 b \sigma_{1}}{2 b-\sigma_{1}}$. To find the competing firm characteristics that satisfy equation (10), we shall first eliminate those firm types for whom this condition will not be met i.e., we shall identify $\sigma_{1}, \sigma_{2}$ for whom $\pi_{1 a}^{F}\left(s_{1}^{F^{*}}, s_{2}^{F^{*}}\right)<\pi_{1 c}^{F}\left(s_{1}^{F}>s_{2}^{F^{*}}\right)$ or as simplified below in equation (11).

$$
s_{1}^{F}\left[\sigma_{1}-\frac{s_{1}^{F}\left(b+\sigma_{1}\right)}{b}-\frac{2 b \sigma_{1} \sigma_{2}}{4 b\left(b+\sigma_{2}\right)+\sigma_{1} \sigma_{2}}\right]-\frac{b^{2} \sigma_{1}^{2} \sigma_{2}{ }^{2}}{\left[4 b\left(b+\sigma_{2}\right)+\sigma_{1} \sigma_{2}\right]^{2}}>0
$$

We can reduce (11) to a quadratic expression of the form $\left(s_{1}^{F}-x\right)\left(s_{1}^{F}-y\right)<0$, where

$$
\begin{aligned}
& x=\frac{b \sigma_{1}\left(4 b^{2}+2 b \sigma_{2}+\sigma_{1} \sigma_{2}-\sqrt{16 b^{4}+16 b^{3} \sigma_{2}+8 b^{2} \sigma_{1} \sigma_{2}+\sigma_{1}^{2} \sigma_{2}^{2}}\right)}{2\left(b+\sigma_{1}\right)\left(4 b\left(b+\sigma_{2}\right)+\sigma_{1} \sigma_{2}\right)} \\
& \text { and } \\
& y=\frac{b \sigma_{1}\left(4 b^{2}+2 b \sigma_{2}+\sigma_{1} \sigma_{2}+\sqrt{16 b^{4}+16 b^{3} \sigma_{2}+8 b^{2} \sigma_{1} \sigma_{2}+\sigma_{1}^{2} \sigma_{2}^{2}}\right)}{2\left(b+\sigma_{1}\right)\left(4 b\left(b+\sigma_{2}\right)+\sigma_{1} \sigma_{2}\right)}
\end{aligned}
$$

Note that since $4 b^{2}+2 b \sigma_{2}+\sigma_{1} \sigma_{2}>\sqrt{16 b^{4}+16 b^{3} \sigma_{2}+8 b^{2} \sigma_{1} \sigma_{2}+\sigma_{1}{ }^{2} \sigma_{2}{ }^{2}}$, both terms are positive. (11) implies that either $y<s_{1}^{F}<x$ or $x<s_{1}^{F}<y$. Since $x<y$, we need only to consider $x<s_{1}^{F}<y$. Further, since we are considering $s_{1}^{F}>s_{2}^{F^{*}}$, to eliminate the possibility that $\pi_{1 a}^{F}\left(s_{1}^{F^{*}}, s_{2}^{F^{*}}\right)<\pi_{1 c}^{F}\left(s_{1}^{F}>s_{2}^{F^{*}}\right)$ we need to find when $y \leq s_{2}^{F^{*}} . \quad$ Using (7) and (12):

$$
s_{2}^{F^{*}}-y=\frac{b\left(4 b^{2} \sigma_{2}-4 b^{2} \sigma_{1}+2 b \sigma_{1} \sigma_{2}-\sigma_{1}^{2} \sigma_{2}-\sigma_{1} \sqrt{16 b^{4}+16 b^{3} \sigma_{2}+8 b^{2} \sigma_{1} \sigma_{2}+\sigma_{1}^{2} \sigma_{2}^{2}}\right)}{2\left(b+\sigma_{1}\right)\left(4 b\left(b+\sigma_{2}\right)+\sigma_{1} \sigma_{2}\right)} \geq 0
$$

$$
\Rightarrow \sigma_{2} \geq \frac{8 b^{2} \sigma_{1}}{4 b^{2}-\sigma_{1}^{2}}
$$




$$
\sigma_{1}<2 b, \quad \sigma_{2} \geq \frac{8 b^{2} \sigma_{1}}{4 b^{2}-\sigma_{1}^{2}}
$$

Similarly for Firm 2, equations (16) and (17) need to be satisfied:

$$
\begin{aligned}
& \pi_{2 c}^{F}\left(s_{1}^{F^{*}}, s_{2}^{F^{*}}\right) \geq \pi_{2 b}^{F}\left(s_{2}^{F}=s_{1}^{F^{*}}\right) \\
& \pi_{2 c}^{F}\left(s_{1}^{F^{*}}, s_{2}^{F^{*}}\right) \geq \pi_{2 a}^{F}\left(s_{2}^{F}<s_{1}^{F^{*}}\right)
\end{aligned}
$$

Equation (16) is always true as $\frac{b^{2} \sigma_{2}^{2}\left(4 b^{2}-2 b \sigma_{1}+\sigma_{1}^{2}+4 b \sigma_{2}-2 \sigma_{1} \sigma_{2}\right)}{\left[4 b\left(b+\sigma_{2}\right)+\sigma_{1} \sigma_{2}\right]^{2}} \geq 0$ for $\sigma_{1}<2 b$.

Equation (17) can be written as $s_{2}^{F}\left[\frac{\sigma_{1} \sigma_{2}^{2}}{4 b\left(b+\sigma_{2}\right)+\sigma_{1} \sigma_{2}}-s_{2}^{F}\right]-\frac{4 b^{3} \sigma_{j}^{2}\left(b+\sigma_{j}\right)}{\left[4 b\left(b+\sigma_{j}\right)+\sigma_{i} \sigma_{j}\right]^{2}} \leq 0$ and reduced to $\left(s_{2}^{F}-w\right)\left(s_{2}^{F}-z\right) \geq 0$, where

$$
\begin{aligned}
& w=\frac{4 b^{2} \sigma_{1} \sigma_{2}^{2}+4 b \sigma_{1} \sigma_{2}^{3}+\sigma_{1}^{2} \sigma_{2}^{2}-\sqrt{\sigma_{2}^{2}\left(4 b\left(b+\sigma_{2}\right)+\sigma_{1} \sigma_{2}\right)^{2}\left(\sigma_{1}^{2} \sigma_{2}^{2}-16 b^{3} \sigma_{2}-16 b^{4}\right)}}{2\left[4 b\left(b+\sigma_{2}\right)+\sigma_{1} \sigma_{2}\right]^{2}} \\
& z=\frac{4 b^{2} \sigma_{1} \sigma_{2}^{2}+4 b \sigma_{1} \sigma_{2}^{3}+\sigma_{1}^{2} \sigma_{2}^{2}+\sqrt{\sigma_{2}^{2}\left(4 b\left(b+\sigma_{2}\right)+\sigma_{1} \sigma_{2}\right)^{2}\left(\sigma_{1}{ }^{2} \sigma_{2}{ }^{2}-16 b^{3} \sigma_{2}-16 b^{4}\right)}}{2\left[4 b\left(b+\sigma_{2}\right)+\sigma_{1} \sigma_{2}\right]^{2}}
\end{aligned}
$$

Note that since

$4 b^{2} \sigma_{1} \sigma_{2}{ }^{2}+4 b \sigma_{1} \sigma_{2}{ }^{3}+\sigma_{1}{ }^{2} \sigma_{2}{ }^{2}>\sqrt{\sigma_{2}{ }^{2}\left(4 b\left(b+\sigma_{2}\right)+\sigma_{1} \sigma_{2}\right)^{2}\left(\sigma_{1}^{2} \sigma_{2}{ }^{2}-16 b^{3} \sigma_{2}-16 b^{4}\right)}, \quad$ both $\quad$ terms are positive. (17) is satisfied if $z \geq s_{2}^{F} \leq w$ or $z \leq s_{2}^{F} \geq w$. Since $w<z$ and $s_{2}^{F}<s_{1}^{F^{*}}$, a sufficient condition is $s_{1}^{F^{*}} \leq w$, which is always true for $\sigma_{1}<2 b$ :

$$
\frac{4 b \sigma_{1} \sigma_{2}\left(\sigma_{2}{ }^{2}-b \sigma_{2}-2 b^{2}\right)+\sigma_{1}^{2} \sigma_{2}{ }^{2}\left(\sigma_{2}-2 b\right)-\sqrt{\sigma_{2}{ }^{2}\left(4 b\left(b+\sigma_{2}\right)+\sigma_{1} \sigma_{2}\right)^{2}\left(\sigma_{1}{ }^{2} \sigma_{2}{ }^{2}-16 b^{3} \sigma_{2}-16 b^{4}\right)}}{2\left[4 b\left(b+\sigma_{2}\right)+\sigma_{1} \sigma_{2}\right]^{2}} \geq 0
$$


Hence the conditions identified in equation (15) are indeed necessary and sufficient. Since we derive the firm parameters endoge-

nously we can see that an asymmetric equilibrium exists only when $\sigma_{1}<2 b, \sigma_{2} \geq \frac{8 b^{2} \sigma_{1}}{4 b^{2}-\sigma_{1}^{2}}$.

(ii) Let there be a symmetric equilibrium given by $s_{1}^{F^{*}}=s_{2}^{F^{*}}$ such that

$$
\pi_{1}^{F}\left(s_{1}^{F^{*}}, s_{2}^{F^{*}}\right) \geq \pi_{1}^{F}\left(s_{1}^{F}, s_{2}^{F^{*}}\right) \quad ; \quad \pi_{2}^{F}\left(s_{1}^{F^{*}}, s_{2}^{F^{*}}\right) \geq \pi_{2}^{F}\left(s_{1}^{F^{*}}, s_{2}^{F}\right)
$$

For Firm 1 the above implies $\pi_{1 b}^{F}\left(s_{1}^{F^{*}}, s_{2}^{F^{*}}\right) \geq \pi_{1 a}^{F}\left(s_{1}^{F}<s_{2}^{F^{*}}\right)$ and $\pi_{1 b}^{F}\left(s_{1}^{F^{*}}, s_{2}^{F^{*}}\right) \geq \pi_{1 c}^{F}\left(s_{1}^{F}>s_{2}^{F^{*}}\right)$. Let us first consider the case when Firm 1 offers some service higher than $s_{1}^{F^{*}}=s_{2}^{F^{*}}$, i.e. some $s_{1}^{F}=s_{2}^{F^{*}}+k$ where $k>0$.

In order for $\pi_{1 b}^{F}\left(s_{1}^{F^{*}}, s_{2}^{F^{*}}\right) \geq \pi_{1 c}^{F}\left(s_{1}^{F}>s_{2}^{F^{*}}\right)$, we need

$$
\frac{2 b k^{2}+4 b k s_{2}^{F^{*}}-2 b k \sigma_{1}+2 k^{2} \sigma_{1}-b \sigma_{1} s_{2}^{F^{*}}+6 k \sigma_{1} s_{2}^{F^{*}}+3 \sigma_{1} s_{2}^{F^{* 2}}}{2 b} \geq 0
$$

To identify conditions necessary for (21) to hold $\forall k>0$, consider the limit: $\lim _{k \rightarrow 0} \frac{2 b k^{2}+4 b k s_{2}^{F^{*}}-2 b k \sigma_{1}+2 k^{2} \sigma_{1}-b \sigma_{1} s_{2}^{F^{*}}+6 k \sigma_{1} s_{2}^{F^{*}}+3 \sigma_{1} s_{2}^{F^{* 2}}}{2 b}=3 \sigma_{1} s_{2}^{F^{* 2}}-b \sigma_{1} s_{2}^{F^{*}}$. We can see that $s_{2}^{F^{*}} \geq \frac{b}{3}$ is both necessary and sufficient. Similarly, consider the case where the firm offers some service less than $s_{1}^{F^{*}}=s_{2}^{F^{*}}$, i.e. some $s_{1}^{F}=s_{2}^{F^{*}}-l$ where $l>0$. In order for $\pi_{1 b}^{F}\left(s_{1}^{F^{*}}, s_{2}^{F^{*}}\right) \geq \pi_{1 a}^{F}\left(s_{1}^{F}<s_{2}^{F^{*}}\right)$, we need

$$
\frac{2 b l^{2}-4 b l s_{2}^{F^{*}}+b \sigma_{1} s_{2}^{F^{*}}+2 l \sigma_{1} s_{2}^{F^{*}}-3 \sigma_{1} s_{2}^{F^{* 2}}}{2 b} \geq 0
$$

Again, we need to establish that $\quad \pi_{1 b}^{F}\left(s_{1}^{F^{*}}, s_{2}^{F^{*}}\right) \geq \pi_{1 c}^{F}\left(s_{1}^{F}>s_{2}^{F^{*}}\right) \forall k>0$. Since $\lim _{k \rightarrow 0} \frac{2 b l^{2}-4 b l s_{2}^{F^{*}}+b \sigma_{1} s_{2}^{F^{*}}+2 l \sigma_{1} s_{2}^{F^{*}}-3 \sigma_{1} s_{2}^{F^{* 2}}}{2 b}=b \sigma_{1} s_{2}^{F^{*}}-3 \sigma_{1} s_{2}^{F^{* 2}}, \quad s_{2}^{F^{*}} \leq \frac{b}{3} \quad$ is both necessary and sufficient for equation (22) to be true, with the necessary condition that $\sigma_{1} \geq 2 b$. By symmetry, we have the conditions for Firm 2. This implies that when both firm parameters are given by $\sigma_{1}, \sigma_{2} \geq 2 b$, the symmetric equilibrium and respective profits are given by

$$
\left(s_{1}^{F^{*}}, s_{2}^{F^{*}}\right)=\left(\frac{b}{3}, \frac{b}{3}\right) ;\left(\pi_{1}^{F^{*}}, \pi_{2}^{F^{*}}\right)=\left(\frac{b\left(\sigma_{1}-b\right)}{9}, \frac{b\left(\sigma_{2}-b\right)}{9}\right)
$$


Since we derive the firm parameters endogenously, we can see that the symmetric equilibrium exists iff $\sigma_{1}, \sigma_{2} \geq 2 b$.

Proof of Lemma 3: Symmetric equilibrium when both firms offer variable services

The profit function of Firm 1 (and by symmetry, Firm 2) can be expressed as:

$$
\pi_{1}^{V}=\left\{\begin{array}{c}
\pi_{1 a}^{V}=\frac{\sigma_{1} s_{1}^{2}}{2 b}-s_{1}^{2} \quad \text { if } \quad\left(s_{1}<s_{2}\right) \\
\pi_{1 b}^{V}=\frac{\sigma_{1} s_{1}}{2}-\frac{\left(\sigma_{1}+2 b\right) s_{1}^{2}}{2 b} \quad \text { if } \quad\left(s_{1}=s_{2}\right) \\
\pi_{1 c}^{V}=\sigma_{1} s_{1}-\frac{\sigma_{1} s_{2}{ }^{2}}{2 b}-\frac{\left(\sigma_{1}+b\right) s_{1}{ }^{2}}{b} \quad \text { if } \quad\left(s_{1}>s_{2}\right)
\end{array}\right.
$$

Assume that there exists a symmetric equilibrium given by $s_{1}^{N F^{*}}=s_{2}^{N F^{*}}$. If this pair is indeed an equilibrium then equation (25) needs to be satisfied.

$$
\pi_{1}^{V}\left(s_{1}^{V^{*}}, s_{2}^{V^{*}}\right) \geq \pi_{1}^{V}\left(s_{1}^{V}, s_{2}^{V^{*}}\right) ; \pi_{2}^{V}\left(s_{1}^{V^{*}}, s_{2}^{V^{*}}\right) \geq \pi_{2}^{V}\left(s_{1}^{V^{*}}, s_{2}^{V}\right)
$$

Breaking down Firm 1 's analysis into two cases, i.e. $\pi_{1 b}^{V}\left(s_{1}^{V^{*}}, s_{2}^{V^{*}}\right) \geq \pi_{1 a}^{V}\left(s_{1}^{V}<s_{2}^{V^{*}}\right)$ and $\pi_{1 b}^{V}\left(s_{1}^{V^{*}}, s_{2}^{V^{*}}\right) \geq \pi_{1 c}^{V}\left(s_{1}^{V}>s_{2}^{V^{*}}\right)$, we first examine the case when Firm 1 offers higher services, i.e. $s_{1}^{V}=s_{2}^{V^{*}}+k$ for some $k>0$. For $\pi_{1 b}^{V}\left(s_{1}^{V^{*}}, s_{2}^{V^{*}}\right) \geq \pi_{1 c}^{V}\left(s_{1}^{V}>s_{2}^{V^{*}}\right)$ we need

$$
\frac{2 b k^{2}+4 b k s-2 b k \sigma_{1}+2 k^{2} \sigma_{1}-b \sigma_{1} s_{2}^{V^{*}}+4 k \sigma_{1} s_{2}^{V^{*}}+2 \sigma_{1} s_{2}^{V^{* 2}}}{2 b} \geq 0
$$

Since we need to establish that $\pi_{1 b}^{V}\left(s_{1}^{V^{*}}, s_{2}^{V^{*}}\right) \geq \pi_{1 c}^{V}\left(s_{1}^{V}>s_{2}^{V^{*}}\right) \forall k>0$, and $\lim _{k \rightarrow 0} \frac{2 b k^{2}+4 b k s-2 b k \sigma_{1}+2 k^{2} \sigma_{1}-b \sigma_{1} s_{2}^{V^{*}}+4 k \sigma_{1} s_{2}^{V^{*}}+2 \sigma_{1} s_{2}^{V^{* 2}}}{2 b}=2 \sigma_{1} s_{2}^{V^{* 2}}-b \sigma_{1} s_{2}^{V^{*}}, \quad s_{2}^{V^{*}} \geq \frac{b}{2} \quad$ is both necessary and sufficient for equation (26) to be true. Similarly if the firm considers services less than $s_{1}^{V^{*}}=s_{2}^{V^{*}}$, i.e. $s_{1}^{N F}=s_{2}^{N F^{*}}-l$ for some $l>0$, then for $\pi_{1 b}^{V}\left(s_{1}^{V^{*}}, s_{2}^{V^{*}}\right) \geq \pi_{1 a}^{V}\left(s_{1}^{V}<s_{2}^{V^{*}}\right)$, we need

$$
\frac{2 b l^{2}-4 b l s_{2}^{V^{*}}-l^{2} \sigma_{1}+b \sigma_{1} s_{2}^{V^{*}}+2 l \sigma_{1} s_{2}^{V^{*}}-2 \sigma_{1} s_{2}^{V^{* 2}}}{2 b} \geq 0
$$

Again, we need to establish $\quad$ that $\quad \pi_{1 b}^{V}\left(s_{1}^{V^{*}}, s_{2}^{V^{*}}\right) \geq \pi_{1 c}^{V}\left(s_{1}^{V}>s_{2}^{V^{*}}\right) \forall k>0$. Since $\lim _{k \rightarrow 0} \frac{2 b l^{2}-4 b l s_{2}^{V^{*}}-l^{2} \sigma_{1}+b \sigma_{1} s_{2}^{V^{*}}+2 l \sigma_{1} s_{2}^{V^{*}}-2 \sigma_{1} s_{2}^{V^{* 2}}}{2 b}=b \sigma_{1} s_{2}^{V^{*}}-2 \sigma_{1} s_{2}^{V^{* 2}}, s_{2}^{V^{*}} \geq \frac{b}{2}$ is both necessary 
and sufficient for equation (27) to be true, with the necessary condition that $\sigma_{1}>2 b$. Notice that $\frac{b}{2}$ is the maximum level of service that any firm would offer in the market as the $s_{c}^{*}$ of the consumer with the highest $\frac{p}{r}$ ratio is $\frac{b}{2}$, i.e., there is no consumer in the market will use any services greater than this bound. We can derive Firm 2's strategy by symmetry and hence conclude that a symmetric equilibrium exists for firm parameters given by $\sigma_{1}, \sigma_{2}>2 b$, where the equilibrium service-pair and the respective profits of the two firms are

$$
\left(s_{1}^{V^{*}}, s_{2}^{V^{*}}\right)=\left(\frac{b}{2}, \frac{b}{2}\right) ;\left(\pi_{1}^{V^{*}}, \pi_{2}^{V^{*}}\right)=\left(\frac{b\left(\sigma_{1}-2 b\right)}{8}, \frac{b\left(\sigma_{2}-2 b\right)}{8}\right)
$$

Notice that when $\sigma_{1}<2 b$, the firm will never opt to offer services less than his competitor as $\pi_{1 a}^{V}$ is negative. By symmetry this implies that when $\sigma_{2}<2 b$, Firm 2 will also not consider offering services less than his competitor and thus there can be no asymmetric equilibrium. Further, from our earlier discussion we know that for symmetric equilibrium, the non-negative profit condition requires that a firm's marginal value for information be greater than or equal to $2 b$ and hence equilibrium fail to exist when $\sigma_{1}, \sigma_{2}<2 b$

Proof of Lemma 4: Asymmetric equilibrium when only one firm offers variable services

The profit functions of Firm 1 and Firm 2) can be respectively expressed as:

$$
\begin{aligned}
& \pi_{1}^{\tilde{V}}=\left\{\begin{array}{c}
\pi_{1 a}^{\tilde{V}}=s_{1}\left(\frac{\sigma_{1} s_{2}}{b}-s_{1}\right) \quad \text { if }\left(s_{1}<s_{2}\right) \\
\pi_{1 b}^{\tilde{V}}=\frac{s_{1}\left(\sigma_{1}-2 s_{1}\right)}{2} \quad \text { if } \quad\left(s_{1}=s_{2}\right) \\
\pi_{1 c}^{\tilde{V}}=\sigma_{1} s_{1}-\frac{\left(\sigma_{1}+b\right) s_{1}^{2}}{b} \quad \text { if }\left(s_{1}>s_{2}\right)
\end{array}\right. \\
& \pi_{2}^{\widetilde{F}}=\left\{\begin{array}{c}
\pi_{2 a}^{\widetilde{F}}=\frac{\sigma_{2} s_{2}\left(b-s_{1}-s_{2}\right)}{b}-s_{2}^{2} \quad \text { if }\left(s_{1}<s_{2}\right) \\
\pi_{2 b}^{\widetilde{F}}=\frac{\sigma_{2} s_{2}}{2}-\frac{\left(\sigma_{2}+b\right) s_{2}^{2}}{b} \quad \text { if }\left(s_{1}=s_{2}\right) \\
\pi_{2 c}^{\widetilde{F}}=-s_{2}^{2} \quad \text { if }\left(s_{1}>s_{2}\right)
\end{array}\right.
\end{aligned}
$$

Recall that there can be no symmetric equilibrium as the variable-service firm can always corner the entire market by offering a service that is equal to or higher than that offered by the fixed-service competitor. And since there is no equilibrium in the region $s_{1}>s_{2}$, if there is any asymmetric equilibrium it can only exist in $s_{1}<s_{2}$. Let $\left\{s_{1}^{*}, \tilde{F}_{2}^{*}\left(s_{1} \tilde{V}^{*}<s_{2}^{*}\right)\right\}$ be an equi- 
librium pair. To be an equilibrium strategy, $s_{1}^{V^{*}}$ must maximize $\pi_{1}^{V}\left(s_{1}^{V}, s_{2}^{F^{*}}\right)$ not only on the interval $s_{1}^{V^{V}}<s_{2}^{F^{*}}$ but on the whole domain of $s_{1}^{\widetilde{V}}$, i.e.,

$$
\pi_{1}^{\widetilde{V}}\left(s_{1}^{V^{*}}, \tilde{F}_{2}^{*}\right) \geq \pi_{1}^{\widetilde{V}}\left(s_{1}^{\widetilde{V}}, \tilde{s}_{2}^{*}\right) ; \pi_{2}^{\widetilde{F}}\left(s_{1}^{V^{*}}, \tilde{s}_{2}^{*}\right) \geq \pi_{2}^{\widetilde{F}}\left(s_{1}^{\tilde{V}^{*}}, \tilde{s}_{2}^{\widetilde{F}}\right)
$$

Solving simultaneously the best responses of the two firms in their respective profit regions, we have $\frac{\sigma_{1}}{2 b} s_{2}=\frac{\left(b-s_{1}\right) \sigma_{2}}{2\left(b+\sigma_{2}\right)}$

which yields:

$$
\left(s_{1}^{V^{*}}, s_{2}^{F^{*}}\right)=\left(\frac{b \sigma_{1} \sigma_{2}}{4 b\left(b+\sigma_{2}\right)+\sigma_{1} \sigma_{2}}, \frac{2 b^{2} \sigma_{2}}{4 b\left(b+\sigma_{2}\right)+\sigma_{1} \sigma_{2}}\right)
$$

Putting (32) into the respective profit functions of the two firms:

$$
\left(\pi_{1}^{\widetilde{V}^{*}}, \pi_{2}^{\tilde{F}^{*}}\right)=\left(\frac{b^{2} \sigma_{1}^{2} \sigma_{2}^{2}}{\left[4 b\left(b+\sigma_{2}\right)+\sigma_{1} \sigma_{2}\right]^{2}}, \frac{4 b^{3} \sigma_{2}^{2}\left(b+\sigma_{2}\right)}{\left[4 b\left(b+\sigma_{2}\right)+\sigma_{1} \sigma_{2}\right]^{2}}\right)
$$

Now we need to verify that equation (31) is indeed true. For Firm 1, we can breakdown the necessary condition as

$$
\begin{aligned}
& \pi_{1 a}^{\widetilde{V}}\left(s_{1}^{\tilde{V}^{*}}, \tilde{F}_{2}^{*}\right) \geq \pi_{1 b}^{\widetilde{V}}\left(s_{1}^{\tilde{V}}=s_{2}^{\tilde{F}^{*}}\right) \\
& \text { and } \\
& \pi_{1 a}^{\widetilde{N F}}\left(s_{1}^{N F^{*}}, \widetilde{F}_{2}^{*}\right) \geq \pi_{1 c}^{\widetilde{N F}}\left(\widetilde{N_{1}^{N F}}>s_{2}^{*}\right) \\
& \text { Incorporating the equilibrium services in Firm 1's profit functions given in (33) and simplifying (34), we have } \\
& \frac{4 b^{3} \sigma_{2}\left(b \sigma_{2}-b \sigma_{1}-\sigma_{1} \sigma_{2}\right)}{\left(4 b^{2}+4 b \sigma_{2}+\sigma_{1} \sigma_{2}\right)^{2}} \geq 0 . \text { And since } \sigma_{2}>0, \text { this implies } \\
& \sigma_{1}<b, \sigma_{2} \geq \frac{b \sigma_{1}}{b-\sigma_{1}}
\end{aligned}
$$

In order to identify conditions for (35) to hold, let Firm 1 offer $s_{2}^{*}+k$ for some $k>0$. We need to find firm parameters such that $\pi_{1 a}^{\tilde{V}}\left(s_{1}^{\tilde{V}^{*}}, s_{2}^{F^{*}}\right) \geq \pi_{1 c}^{\tilde{V}}\left(s_{1}^{\tilde{V}}>s_{2}^{\tilde{F}^{*}}\right)$, i.e., 


$$
\begin{aligned}
& \frac{b^{2} \sigma_{1}^{2} \sigma_{2}^{2}}{\left[4 b\left(b+\sigma_{2}\right)+\sigma_{1} \sigma_{2}\right]^{2}}-\left\{-\frac{1}{b}\left[\left(k+\frac{2 b^{2} \sigma_{2}}{4 b\left(b+\sigma_{2}\right)+\sigma_{1} \sigma_{2}}\right)\right.\right. \\
& \left.\left.*\left(\sigma_{1} \cdot\left(k+\frac{2 b^{2} \sigma_{2}}{4 b\left(b+\sigma_{2}\right)+\sigma_{1} \sigma_{2}}\right)+b \cdot\left(k-\sigma_{1}+\frac{2 b^{2} \sigma_{2}}{4 b\left(b+\sigma_{2}\right)+\sigma_{1} \sigma_{2}}\right)\right)\right]\right\} \geq 0
\end{aligned}
$$

Simplifying equation (37) and ensuring non-negative $k$, we get

$$
\sigma_{1}<\frac{2 b}{1+\sqrt{2}}, \sigma_{2} \geq \frac{8 b^{2} \sigma_{1}}{4 b^{2}-4 b \sigma_{1}-\sigma_{1}^{2}}
$$

We now need to ensure that the equilibrium is valid from the second firm's perspective by verifying the second part of (31). As one region is infeasible, we need to only verify that $\pi_{2 c}^{F}\left(s_{1}^{V^{*}}, s_{2}^{F^{*}}\right) \geq \pi_{2 b}^{F}\left(s_{2}^{F}=s_{1}^{V^{*}}\right)$ which is always true for the equilibrium set of services. Therefore, the necessary and sufficient condition for the asymmetric equilibrium is given by (38), which also satisfies (36).

Part III: Proof of Propositions

Propositions 1 and 2 can be derived from comparing the equilibria conditions and the respective profits for the firms under different equilibria in the service-level subgames given in the lemmas (all proofs are available in the companion appendix). By comparing the conditions under which asymmetric equilibria in the full game is possible (refer to Lemmas 1 and 4 for detail), two equilibria, $\left\{\left(s_{1}^{F}, \frac{\mathrm{b} \sigma_{1} \sigma_{2}}{4 \mathrm{~b}\left(\mathrm{~b}+\sigma_{2}\right)+\sigma_{1} \sigma_{2}}\right) ;\left(s_{2}^{F}, \frac{2 \mathrm{~b}^{2} \sigma_{2}}{4 \mathrm{~b}\left(\mathrm{~b}+\sigma_{2}\right)+\sigma_{1} \sigma_{2}}\right)\right\} ;\left\{\left(s_{1}^{V}, \frac{\mathrm{b} \sigma_{1} \sigma_{2}}{4 \mathrm{~b}\left(\mathrm{~b}+\sigma_{2}\right)+\sigma_{1} \sigma_{2}}\right) \&\left(s_{2}^{F}, \frac{2 \mathrm{~b}^{2} \sigma_{2}}{4 \mathrm{~b}\left(\mathrm{~b}+\sigma_{2}\right)+\sigma_{1} \sigma_{2}}\right)\right\}$, are possible candidates as equilibria in the full game when $\sigma_{1} \in\left[0, \frac{2 b}{1+\sqrt{2}}\right]$ and $\sigma_{2} \in\left[\frac{8 \sigma_{1} \mathrm{~b}^{2}}{4 \mathrm{~b}^{2}-4 b \sigma_{1}-\sigma_{1}^{2}},+\infty\right]$. Since firms' profit functions are the same in the two cases (i.e. firms are indifferent between fixed-fixed/variable-fixed strategies in the first stage), both equilibria are SPNEs. When $\sigma_{1} \in[0,2 b)$ and $\sigma_{2} \in\left[\frac{8 \sigma_{1} \mathrm{~b}^{2}}{4 \mathrm{~b}^{2}-4 b \sigma_{1}-\sigma_{1}^{2}}, \frac{8 \sigma_{1} \mathrm{~b}^{2}}{4 \mathrm{~b}^{2}-4 b \sigma_{1}-\sigma_{1}^{2}}\right)$, only one equilibrium $\left\{\left(\left\{s_{1}^{F}, \frac{\mathrm{b} \sigma_{1} \sigma_{2}}{4 \mathrm{~b}\left(\mathrm{~b}+\sigma_{2}\right)+\sigma_{1} \sigma_{2}}\right) ;\left(s_{2}^{F}, \frac{2 \mathrm{~b}^{2} \sigma_{2}}{4 \mathrm{~b}\left(\mathrm{~b}+\sigma_{2}\right)+\sigma_{1} \sigma_{2}}\right)\right\}\right)$ is possible; hence contributing to a unique SPNE. When the MVIs of both firms are sufficiently large, two symmetric equilibria emerge: $\left\{\left(s_{1}^{F}, \frac{b}{3}\right) ;\left(s_{2}^{F}, \frac{b}{3}\right)\right\}$ and $\left\{\left(s_{1}^{V}, \frac{b}{2}\right) ;\left(s_{2}^{V}, \frac{b}{2}\right)\right\}$ (lemmas 2 and 3 ). By comparing profits of the firms, we notice that the former (latter) equilibrium domi- 
nates when $\sigma_{i} \in[2 b, 10 b), i \in\{1,2\} \quad\left(\sigma_{i} \in[10 b,+\infty), i \in\{1,2\}\right)$; hence resulting in a unique SPNE for different firm types.

For proof of Proposition 3, first consider the equilibria under which both firms are characterized by high MVls $\left(\sigma_{i} \geq 2 b, i \in\{1,2\}\right)$. In the case of fixed-services, both firms offer $s_{1}^{F^{*}}=s_{2}^{F^{*}}=\frac{b}{3}$. For notation simplicity we denote this service level as $s^{F^{*}}$. Consumers with break-even level of services less than the equilibrium service level $\left(s_{c}^{0} \leq \frac{b}{3}\right)$, would not use any service. The disutilities of these consumers are given by the summation of their respective $s_{c}^{*}$. The remaining consumers suffer disutilities depending on the relative distances of their respective $s_{c}^{*}$ and $s^{F^{*}}$. Therefore, the total disutilities suffered by consumers are given by:

$$
\int_{0}^{\frac{s^{F^{*}}}{2}} x \cdot U\left(s_{c}^{*}\right) d x+\int_{\frac{s^{F^{*}}}{2}}^{s^{F^{*}}}\left(s^{F^{*}}-x\right) U\left(s_{c}^{*}\right) d x+\int_{s^{*}}^{\frac{b}{2}}\left(x-s^{F^{*}}\right) U\left(s_{c}^{*}\right) d x=\frac{b}{12}
$$

And the consumer surplus is given by $w^{*}-\frac{b}{12}$ where $w^{*}$ denotes the maximum attainable consumer surplus. Since firm surplus $=\pi_{1}^{F^{*}}+\pi_{2}^{F^{*}}$, the total welfare under fixed-services is:

$$
w^{*}-\frac{b}{12}+\frac{b\left(\sigma_{1}-b\right)}{9}+\frac{b\left(\sigma_{2}-b\right)}{9}=w^{*}-\frac{8 b^{2}-b\left(4\left(\sigma_{1}+\sigma_{2}\right)-3\right)}{36}
$$

In the case of variable services, both firms offer $s_{1}^{V^{*}}=s_{2}^{V^{*}}=\frac{b}{2}$. The service level offered by the firms satisfies even the consumer with the highest demand for personalization. Since consumers are free to choose the level of personalization to adopt and all consumers enjoy their respective optimal level of services, all consumers attain their highest utilities $\left(w^{*}\right)$.

Since firm surplus is $\pi_{1}^{V^{*}}+\pi_{2}^{V^{*}}$, and the total welfare under variable services is:

$$
w^{*}+\frac{b\left(\sigma_{1}-2 b\right)}{8}+\frac{b\left(\sigma_{2}-2 b\right)}{8}=w^{*}-\frac{4 b^{2}-b\left(\sigma_{1}+\sigma_{2}\right)}{8}
$$

